\title{
An Optimization Framework for the Integration of Water Management and Shale Gas Supply Chain Design
}

\author{
Omar J. Guerraa, Andrés J. Calderón ${ }^{\mathrm{b}}$, Lazaros G. Papageorgioub ${ }^{\mathrm{b}}$ Jeffrey J. \\ Siirolaa, Gintaras V. Reklaitis ${ }^{\mathrm{a}, *}$
}

a School of Chemical Engineering, Purdue University, West Lafayette IN 47907 USA.

b Department of Chemical Engineering, University College London, London WC1E 7JE, UK *Corresponding author. E-mail address: reklaiti@purdue.edu (G.V. Reklaitis).

\begin{abstract}
This study presents the mathematical formulation and implementation of a comprehensive optimization framework for the assessment of shale gas resources. The framework simultaneously integrates water management and the design and planning of the shale gas supply chain, from the shale formation to final product demand centers and from fresh water supply for hydraulic fracturing to water injection and/or disposal. The framework also addresses some issues regarding wastewater quality, i.e. total dissolved solids (TDS) concentration, as well as spatial and temporal variations in gas composition, features that typically arise in exploiting shale formations. In addition, the proposed framework also considers the integration of different modeling, simulation and optimization tools that are commonly used in the energy sector to evaluate the technical and economic viability of new energy sources. Finally, the capabilities of the proposed framework are illustrated through two case studies (A and B) involving 5 well-pads operating with constant and variable gas composition, respectively. The effects of the modeling of variable TDS concentration in the produced wastewater is also addressed in case study B.
\end{abstract}




\section{Introduction}

It is expected that primary energy demand will continue to increase in the next decades. According to the BP Energy Outlook (BP 2014), world primary energy consumption is expected to increase roughly $41 \%$ from 2012 to 2035, with an average annual growth rate of $1.5 \%$. Fossil fuels will remain the major source of energy, with a share of $81 \%$ in 2035 . Among fossil fuels, gas consumption will increase the most by $1.9 \%$ per year. Nearly half of the growth in global gas supply will be provided by shale gas, which is projected to grow $6.5 \%$ per year. Therefore, shale gas resources can play an important role in the energy sector in the next decades. However, the production of shale gas resources depends extensively on production costs and productivity where minor changes in the market conditions can imply significant repercussions on the feasibility and profitability of the development of a shale gas play. In addition, different environmental impacts have been identified associated with the development of shale gas plays. In particular, the depletion and degradation of water sources, as well as the potential for underground water contamination, are major concerns that could and do hinder the development of these resources (Clark et al. 2013; Eaton 2013; Jenner and Lamadrid 2013; Vidic et al. 2013; Warner et al. 2013; Sirrola 2014). Thus, the assessment of shale gas resources is a challenging problem where economic and environmental aspects need to be considered at both the individual field and supply chain decision levels.

Shale gas refers to natural gas trapped within sedimentary rocks, which are characterized by relatively low porosity and permeability when compared to conventional natural gas (see Figure 1 and Table 1). Therefore, shale gas production requires the stimulation of shale formation in order to increase its permeability, facilitating the flow of natural gas from the formation matrix to the well (Guarnone et al. 2012; Mohaghegh 2013; Rivard et al. 2014). Recent advances in horizontal well drilling and hydraulic fracturing technologies have made the stimulation of shale formations and the production of economic volumes of unconventional natural gas feasible (Kinnaman 2011; Olmstead et al. 2013; Vidic and Brantley 2013; Wilson and Durlofsky 2013; Rivard et al. 2014). Despite these developments, the recovery factors of the original gas-in-place for unconventional natural gas, typically in the order of $20-30 \%$, are considerably lower than those for 
conventional natural gas resources, which are commonly between $80 \%$ and $90 \%$ (Kaiser 2012a, 2012b). The production of shale gas involves fluid storage and transport mechanisms, which include nonlinear adsorption/desorption processes, non-Darcy flows, complex flow geometry, and multi-scaled heterogeneity. Given that these phenomena are poorly understood, the modeling and simulation of natural gas production from shale formation have captured the attention of the academic and engineering community in recent years (Clarkson et al. 2011; Dahaghi and Mohaghegh 2011; Bustin and Bustin 2012; Clarkson 2013; Mohaghegh 2013; Patzek et al. 2013; Heller and Zoback 2014; Patwardhan et al. 2014; Wu et al. 2014). A comprehensive review including the characterization of shale gas reservoirs, production techniques and modeling and simulation advances is provided by the authors in Calderón et al. 2015

The production of shale gas requires much more water over its life cycle (13-37 L/G) or 3.63-10.32 gallon/ million Btu) than the production of conventional natural gas, which has a water consumption on the order of 9.3-9.6 L/GJ or 2.59-2.68 gallon/ million Btu (Clark et al. 2013). In the particular case of the Marcellus shale formation, the direct life cycle water consumption is estimated to be between 2,600-21,000 $\mathrm{m}^{3}$ /well or $0.68-5.55$ million gallon/well. Well hydraulic fracturing accounts for about $86 \%$ of the total (direct plus indirect) freshwater consumption excluding gas utilization (Jiang et al. 2014). About $10-40$ percent of the fracturing fluid, which is a mixture of water ( $\approx 90-95$ vol\%), proppants $(\approx 4-9$ vol\%), and chemical modifiers ( $\approx$ less than 1 vol\%), will return to the surface during the first few weeks (1-2 weeks) after fracturing. This wastewater is known as flowback water (Gregory et al. 2011; Slutz et al. 2012; Eaton 2013; Jackson et al. 2014; Sovacool 2014; Vengosh et al. 2014). The typical initial flowback water flow rate could be around $1,000 \mathrm{~m}^{3}$ /day (0.26 million gallon/day). In addition, after the flowback period, water from the formation is produced at the surface in much lower volumes $\left(2-8 \mathrm{~m}^{3} /\right.$ day or $528-2,113$ gallon/day) over the lifetime of the well, this wastewater is known as produced water (Gregory et al. 2011; Barbot et al. 2013; Warner et al. 2013; Nicot et al. 2014; Vengosh et al. 2014). Both flowback and produced water can be characterized by the concentration of total suspended solids (TSS), total dissolved solids (TDS), cations like calcium, magnesium, iron, barium, and strontium, anions including chloride, bicarbonate, phosphate, and sulfate, 
as well as radioactive radium (Slutz et al. 2012; Horner et al. 2013; Vengosh et al. 2014). It is important to note that shale gas wastewater (flowback and produced water) composition varies spatially and temporally (Barbot et al. 2013). Typical TSS concentration varies from 1-500 mg/L for both flowback and produced water, while TDS concentration varies between 5,000-250,000 mg/L and between 10,000-336,000 mg/L for flowback and produced water, correspondingly (Fedotov et al. 2013). As a reference, typical TDS concentration is less than $1,000 \mathrm{mg} / \mathrm{L}$ for fresh water and about $25,000 \mathrm{mg} / \mathrm{L}$ for seawater (Vengosh et al. 2014). Concentration of TDS in wastewater is lower at the beginning and increases as time progresses, given that minerals and organic constituents present in the formation dissolve into the fracturing fluid (Gregory et al. 2011; Slutz et al. 2012). The concentration of TDS is one of the most important evaluation parameters for wastewater treatment economics and management strategy, as it has a direct impact on the maximum amount of the wastewater that can be blended with fresh water to make-up the overall required water for the fracturing fluid (Slutz et al. 2012; Rahm and Riha 2014).

Existing shale gas wastewater management strategies can be classified into the following three categories: disposal, re-use, and recycling (Slutz et al. 2012; Horner et al. 2013; Rahm and Riha 2014). The disposal strategy consists of using fresh water sources for hydraulic fracturing and the disposal of wastewater into injection wells. By contrast, re-use strategy includes the treatment (primary) of wastewater followed by blending with fresh water to obtain the necessary water for the fracturing process. Finally, the recycling strategy consists of more intensive treatment (secondary and /or tertiary) of the wastewater to achieve fresh water quality, either for blending with fresh water to generate the fracturing fluid or for environmental discharge (Slutz et al. 2012; Horner et al. 2013). The optimal wastewater management strategy depends on many factors, including treatment costs, availability of injection wells, disposal costs, blending compatibility between fresh water and treated water, quality of wastewater (i.e. concentration of TDS), logistic constraints, and fracturing fluid specifications.

Since there are a number of important issues regarding shale gas production, such as, water supply and wastewater management, some publications have been focused on the assessment of the impacts and risks of shale gas development on water resources (Nicot 
and Scanlon 2012; Rahm et al. 2013; Vidic et al. 2013; Warner et al. 2013; Jackson et al. 2013; Mitchell et al. 2013; Olmstead et al. 2013; Brantley et al. 2014; Goodwin et al. 2014; Rahm and Riha 2014; Vengosh et al. 2014; Nicot et al. 2014; Pacsi et al. 2014) and on neighboring communities (Jacquet 2014). Similarly, other works have been concentrated on the evaluation and optimization of water supply and wastewater management strategies for shale gas production (Slutz et al. 2012; Horner et al. 2013; Yang et al. 2014; Gao and You 2015). Another important aspects, related to the development of shale gas resources, that have captured the attention of some authors are the assessment of carbon footprint and greenhouse gas emissions (Stephenson et al. 2011; Wang et al. 2011; Burnham et al. 2012; Weber and Clavin 2012; Laurenzi and Jersey 2013; Chang et al. 2014a, 2014b; Field et al. 2014; Heath et al. 2014; Stamford and Azapagic 2014). Additional work has been focused on the optimization and economic evaluation of shale gas production, without or with little attention to water supply and wastewater management (Kaiser 2012a, 2012b; Weijermars 2013, 2014, 2015; Wilson and Durlofsky 2013; Cafaro and Grossmann 2014; Williams-Kovacs and Clarkson 2014; Xia et al. 2015). Some studies have been published addressing the relation of shale gas with environmental and energy security (Kargbo et al. 2010; Bazilian et al. 2014; Knudsen et al. 2014), climate change (Hou et al. 2012; Jenner and Lamadrid 2013; McJeon et al. 2014; Zoback and Arent 2014), and economic and financial aspects (Kinnaman 2011; McGlade et al. 2013; Melikoglu 2014; Weijermars 2014; Calderón et al. 2015a). Additionally, regulations and policies associated with the development of those resources have also been studied (Rahm 2011; Bistline 2014; Konschnik and Boling 2014; Xia et al. 2015).

In recent years, there has been an intense debate regarding whether shale gas produced by hydraulic fracturing is desirable or not (Howarth et al. 2011; Hou et al. 2012; Malakoff 2014; Sovacool 2014). The objective of this work is to provide a systematic tool that enables researchers and stakeholders to assess the merits of exploiting shale gas resources in a certain region while considering its inherent characteristics and restrictions. Accordingly, in this work we present an optimization framework for the assessment of shale gas resources from a supply chain perspective. The proposed framework takes into account different alternatives regarding fresh water supply and wastewater management 
strategies, as well as well-pad design (i.e. number of wells per well-pad, length of each well, and number of hydraulic fractures per well). To the best of the authors' knowledge, this is the first paper addressing water management, well-pad design, as well as shale gas supply chain design and optimization in an integrated fashion. The novelties of the proposed work are summarized as follows:

- Off-line integration of reservoir simulation tools in shale gas supply chain design and planning: Implementation of reservoir simulation techniques to estimate gas production profiles for different configurations of the well-pads. The selection of the candidate well-pad designs is based not only on the economics but also on the water intensity, which is an environmental criterion. Additionally, the off-line integration of reservoir simulators for the design and planning of shale gas supply chains is especially useful in cases where historical production data is not available.

- Off-line integration of geographic information systems for the design of potential infrastructure of shale gas and water supply chains, as well as for the estimation of hydric resources: Use of geographic information systems (ArgcGis 10.2) for the design of the potential infrastructure for gas and water transport and processing. Additionally, ArgcGis is used to carry out a national hydrological balance to estimate water availability based on historical data on precipitation, evapotranspiration, infiltration, and downstream demand.

- Proposed novel formulation of water management aspects: This formulation considers the explicit modeling of water blending for fracturing operation as well as in wastewater treatment plants. The formulation also takes into account, in an explicitly form, constraints on Total Dissolved Solid (TDS) in fracturing operations and wastewater treatment plants. Additionally, the formulation can be easily extended to take into account other wastewater properties such as Total Suspended Solids (TSS). Moreover, the formulation can accommodate spatial and temporal variations in TDS concentration.

- Integration of the design and planning of the gas supply chain along with water management: The optimization framework allows the simultaneous optimization of the decisions involved in the design and planning of the gas supply chain and the water management. Our findings reveal that the assessment of both supply chains (gas and 
water) cannot be decoupled from each other. The full understanding of the intrinsic synergies between these components requires that these types of planning problems be analyzed in an integrated fashion.

The rest of this paper is organized as follows: First, we present the problem statement, including a generic big picture view of shale gas supply chain integrated with water supply and wastewater management options. Then, we present the mathematical formulation of the optimization model, including the economic objective function along with strategic, logistic, and operational constraints. Next, the capabilities of the proposed optimization framework are demonstrated through Case Study A and Case Study B where gas composition is considered to be constant and variable, respectively. Finally, we summarize the contributions of this work and the directions for future work.

\section{Problem statement}

The development of shale gas resources involve many strategic and operational decisions, including the selection of sources of water for fracking processes, selection of well-pads location and design, the design of gas and liquid pipelines network, technology, location, and capacity for wastewater treatment plants, and the location and design of gas processing plants. A generic shale gas supply chain superstructure is presented in Figure 2. The general shale gas supply chain infrastructure includes a set of potential freshwater sources $(f \in F)$ with specific water availability for each time period (WateAvai $(f, t)$ ). Different well-pad designs $(d \in D)$ can be used to produce shale gas from potential wellpads $(w \in W)$, each well-pad having a specific location. In addition, each well-pad design is defined in terms of total number of wells, length and location of each well, and number of hydraulic fractures completed in each well.

Shale gas produced from well-pads can be sent to gas plants $(p \in P)$ either directly or through compressor stations $(c \in C)$. Moreover, produced and flowback water can be either processed in water treatment plants $(h \in H)$ or sent to injection/disposal sites $(s \in S)$ depending on treated water quality and disposal capacity constraints. The shale gas 
is composed of a mix of different chemical species including hydrocarbons like methane, ethane; condensable fractions of propane, butane, iso-butane, etc. and other gases such as carbon dioxide and nitrogen. All those species are defined by the set $i \in I$. Final products from gas processing plants are sent to demand centers. For instance, gas product is sent to methane demand centers to supply demand from power plants, residential sector and external customers. Liquid ethane is sent to ethane demand centers to supply demand from petrochemical facilities and others possible customers. The other liquid hydrocarbons $\left(\mathrm{C}_{3^{+}}\right)$ are considered to be sold to customers at the gas processing plant locations at a given plant-gate price, thus no transportation is required for those products.

\section{Mathematical formulation}

In this section we describe the deterministic optimization model for the design and planning of shale gas supply chains, with water supply and wastewater management considerations. The mathematical model is as follows:

\subsection{Objective function}

The objective function is to maximize the Net Present Value (NPV), defined as the cash flow CashFlow $(t)$ minus capital expenditures Capex $(t)$, associated with the design of the shale gas supply chain, as described in Equation (1). The scalar $\gamma$ represents the annual interest rate and $t$ is the index for time periods, quarters in this case.

$$
\max N P V=\sum_{t} \frac{\operatorname{CashFlow}(t)-\operatorname{Capex}(t)}{(1+\gamma)^{t-1}}
$$

\subsubsection{Cash flow}

Cash flow is defined as the profit before taxes Profit $(t)$ plus depreciation minus tax amount Taxes $(t)$, as described in Equation (2). Here, depreciation is expressed as a linear function of the capital expenditures using a given depreciation rate $\operatorname{Dep} R\left(t^{\prime}, t\right)$.

$$
\operatorname{CashFlow}(t)=\operatorname{Profit}(t)+\sum_{t^{\prime}} \operatorname{DepR}\left(t^{\prime}, t\right) * \operatorname{Capex}\left(t^{\prime}\right)-\operatorname{Taxes}(t) \quad \forall t
$$




\subsubsection{Capital expenditures}

Capital expenditures consist of the sum of the investment in well-pads drilling and hydraulic fracturing, pipelines for transport raw gas, compressor stations, water treatment plants, gas processing plants, and pipeline for deliver final products, as shown in Equation Error! Reference source not found..

$$
\begin{aligned}
\operatorname{Capex}(t)= & \text { CapexWE }(t)+\operatorname{CapexPI}(t)+\operatorname{CapexCO}(t)+\operatorname{CapexWA}(t) \\
& +\operatorname{CapexGA}(t)+\operatorname{CapexP} J(t) \forall t
\end{aligned}
$$

\subsubsection{Profit and taxes}

The profit associated with the shale gas supply chain operation is estimated as the revenue Revenue(t) minus royalties Royalty $(t)$, water transportation cost $\operatorname{Trans} \operatorname{Cos} t(t)$, operating expenditures Opex $(t)$, and depreciation, as defined in Equation Error! Reference source not found.. For periods in which the profit is positive, a taxation charge is typically imposed. The taxation charge is defined as the tax rate $t r$ times profit. Equations Error! Reference source not found. and Error! Reference source not found. guarantee that taxes are applied only when profit is positive: taxes are set to zero otherwise. However, it is important to clarify that in some situations; tax laws allow losses in one or more years to be carried over so as to reduce the tax burden in profitable years. In this case, Equations Error! Reference source not found. and Error! Reference source not found. should be modified accordingly to the tax system that is applicable for the study.

$$
\begin{gathered}
\operatorname{Profit}(t)=\operatorname{Revenue}(t)-\operatorname{Royalty}(t)-\operatorname{Trans} \operatorname{Cos} t(t)-\operatorname{Opex}(t)-\sum_{t^{\prime}} \operatorname{DepR}\left(t^{\prime}, t\right) \\
* \operatorname{Capex}\left(t^{\prime}\right) \quad \forall t
\end{gathered}
$$

$$
\operatorname{Taxes}(t) \geq \operatorname{tr} * \operatorname{Profit}(t) \quad \forall t
$$

$$
\operatorname{Taxes}(t) \geq 0 \quad \forall t
$$

\subsubsection{Revenue}

The revenue from selling final products to markets, is estimated as stated in Equation Error! Reference source not found., where Price $(i, j, t)$ is the price for product $i$ in market $j$ during period $t$ and $\operatorname{FlowPJ}(p, i, j, t)$ is the flow rate of product $i$ from gas plant $p$ 
to demand center $j$ during period $t$. In addition, the variable $\operatorname{ReveC3}(t)$ represents the income from selling $\mathrm{C}_{3+}$ hydrocarbons at gas processing plant locations.

$$
\operatorname{Revenue}(t)=\sum_{j} \sum_{i \mid(i, j) \in l i j} \operatorname{Price}(i, j, t) * \sum_{p} \operatorname{FlowPJ}(p, i, j, t)+\operatorname{ReveC3}(t) \quad \forall t
$$

\subsubsection{Royalties}

Royalties are payment to resource owners for the permission to explore and exploit the resources found in their lands (shale gas in this case); this cost component is modeled through Equation Error! Reference source not found., here scalar roy represents the royalty rate.

$$
\operatorname{Royalty}(t)=\operatorname{roy} * \operatorname{Revenue}(t) \quad \forall t
$$

\subsubsection{Water transportation cost}

Total water transport cost $(\operatorname{TranCost}(t))$ consist of the sum of the cost of transportation from freshwater suppliers to well-pads, from well-pads to water treatment plants, from well-pads to disposal sites, from water treatment plants to well-pads, and from water treatment plants to disposal sites, as shown in Equation Error! Reference source not found..

$$
\operatorname{TranCost}(t)=\operatorname{CostFW}(t)+\operatorname{Cost} W H(t)+\operatorname{CostWS}(t)+\operatorname{Cost} H W(t)+\operatorname{CostHS}(t) \quad \forall t
$$

\subsubsection{Operating expenditures}

Operating expenditures include the annual cost of operating well-pads OpexWE $(t)$, gas pipelines for transporting raw gas from well-pads to either compressor stations OpexWC $(t)$ or gas plants opexWP(t), compressor stations $O$ pexCO $(t)$, water treatment

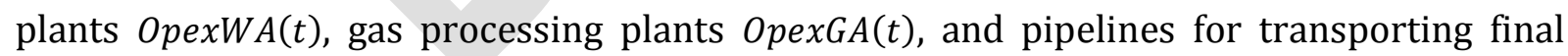
products to demand centers $O \operatorname{exDI}(t)$ are estimated from Equation Error! Reference source not found..

$$
\begin{gathered}
O \operatorname{exx}(t)=O p \operatorname{ex} W E(t)+O p \operatorname{ex} W C(t)+O p \operatorname{ex} W P(t)+O \operatorname{pex} C O(t)+O p \operatorname{ex} W A(t) \\
+O \operatorname{exGA}(t)+O p \operatorname{exDI}(t) \forall t
\end{gathered}
$$




\subsubsection{Investment budget}

Since there is a significant risk associated with the shale gas businesses and at the same time oil and gas companies usually have limited budgets for investment on specific projects, Equation Error! Reference source not found. ensures that capital expenditures do not exceed the maximum capital budget MaxInv that is available for investment on shale gas projects.

$$
\sum_{t} \frac{\operatorname{Capex}(t)}{(1+\gamma)^{t-1}} \leq \operatorname{MaxInv}
$$

\subsection{Freshwater supply}

Freshwater sources are required to provide freshwater for hydraulic fracking at well-pads locations. These sources are constrained in water availability, since local water resources are not infinitely available. In addition, freshwater should be transported from freshwater sources to well-pad locations, which entails a transportation cost.

\subsubsection{Availability}

The availability of freshwater from a specific source may depend on the season, environmental flow, and downstream water demand. Equation Error! Reference source not found. accounts for the freshwater availability restriction, where $\operatorname{Flow} F W(f, w, t)$ is the flow rate of freshwater transported from source $f$ to wellpad location $w$ during period $t$. The linkage between freshwater source and potential wellpad locations is defined by the set $l f w$.

$$
\sum_{w \mid(f, w) \in l f w} F \operatorname{Flow} F W(f, w, t) \leq W a t e A v a i(f, t) \forall f, t
$$

\subsubsection{Acquisition and Transportation costs}

Acquisition and transportation costs related to the supply of freshwater for hydraulic fracking depend on both well-pad location and total freshwater withdrawal, as stated in Equation Error! Reference source not found.. The parameter $\operatorname{CostFres}(f, w)$ refers to the unit transportation cost for freshwater from source $f$ to well-pad location $w$. Similarly, parameter $\operatorname{CostAcq}(f)$ denotes the unit water acquisition cost for source $f$. 


$$
\begin{aligned}
\operatorname{CostFW}(t)= & \sum_{f}\left(\operatorname{CostAcq}(f) * \sum_{w \mid(f, w) \in l f w} \operatorname{Flow} F W(f, w, t)\right. \\
& \left.+\sum_{w \mid(f, w) \in l f w} \operatorname{CostFres}(f, w) * \operatorname{Flow} F(f, w, t)\right) \forall t
\end{aligned}
$$

\subsection{Well-pads}

In order to produce shale gas from potential well-pad locations, vertical and horizontal wells need to be drilled and hydraulically fractured. The water demand for fracking the shale formation as well as wastewater production profiles depends on both well-pad location and design. Well-pad design is expressed in terms of total number of wells, length of each well, and number of hydraulic fractures completed in each well. From the supply chain point of view, the design of well-pads is a key decision variable. In particular, the optimal design for a specific well-pad location can be a function of gas prices, water availability constraints, and petrophysical properties of the formation, such as porosity and permeability. For Instance, the U.S. Energy Information Administration, in 2012, reported that the total average cost, including drilling and completion expenses, per horizontal well in Bakken, Eagle Ford, and Marcellus formations varies between $\begin{array}{lllll}\text { approximately } & \$ 6.5 & \text { million } & \text { and } & \$ 9\end{array}$ (http://www.eia.gov/todayinenergy/detail.cfm?id=7910\&src=email). Therefore, well-pad design is an important variable to be considered when designing a shale gas supply chain.

\subsubsection{Well-pad design}

In this work, well-pad design, location, and timing are considered the most important decisions related to shale gas production. These decisions are captured in the binary variable $\operatorname{WellDes}(d, w, t)$. This variable is equal to one if well-pad design $d$ is selected for potential well-pad $\mathrm{w}$ during period $t$; the variable is equal to zero otherwise. The wellpad designs are decision variables in our model. They are implicitly represented by different potential gas and wastewater production profiles for each well-pad location based on shale gas reservoir simulations. Among these, the most appropriate well-pad design or configuration for each location is selected as well as the timing of drilling operations. Then, 
the binary variable $\operatorname{WellDes}(d, w, t)$ is used to estimate gas and wastewater production profiles for each location, which change with time. Since only one well-pad design can be activated during the whole time horizon for a specific potential well-pad location, the constraint defined in Equation Error! Reference source not found. needs to be imposed on the binary variable $W e l l D e s(d, w, t)$. In addition, for each time period, the total number of wells drilled should not exceed the maximum number of wells MaxWell that can be drilled, as expressed in Equation Error! Reference source not found.. The maximum number of wells MaxWell is determined by the total number of rigs that are available times the number of wells that a single rig can drill during one period of time. Parameter $\operatorname{NumWell}(d)$ is defined as the number of wells considered in design $d$.

$$
\sum_{d} \sum_{t} W e l l D e s(d, w, t) \leq 1 \forall w
$$

$$
\sum_{d} \sum_{w} \operatorname{NumWell}(d) * W e l l D e s(d, w, t) \leq \operatorname{MaxWel} \forall t
$$

\subsubsection{Shale gas production}

Shale gas production is expressed as a function of the well-pad design chosen for each potential well-pad location, as defined in Equation Error! Reference source not found.. Here, the parameter $\operatorname{WellGas}\left(d, w, t^{\prime}\right)$ represents current gas production associated with design $d$ for well-pad $w$ of age $t^{\prime}$. Shale gas production from well-pads can be either sent to compressor stations or directly to gas processing plants, as stated in Equation Error! Reference source not found.. The variable Flow $W C(w, c, t)$ represents the flow rate of shale gas transported from well-pad $w$ to compressor station $c$ during period $t$. Similarly, $\operatorname{Flow} W P(w, p, t)$ represents the flow rate of shale gas transported from well-pad $w$ to gas processing plant $p$ during period $t$. The set $l w c$ contains all of the possible connections between well-pads and compressor stations. Similarly, set lwp contains all of the possible connections between well-pads and gas plants.

$$
\operatorname{ShalProd}(w, t)=\sum_{d} \sum_{t^{\prime} \leq t-1} \operatorname{WellGas}\left(d, w, t^{\prime}\right) * \operatorname{WellDes}\left(d, w, t-t^{\prime}\right) \quad \forall w, t
$$




$$
\operatorname{ShalProd}(w, t)=\sum_{c \mid(w, c) \in l w c} F \operatorname{Flow} W C(w, c, t)+\sum_{p \mid(w, p) \in l w p} \operatorname{FlowWP}(w, p, t) \quad \forall w, t
$$

\subsubsection{Shale gas composition and component flows}

With regard to the shale gas composition, three cases can be considered. First, in order to avoid bilinear terms in the problem formulation, shale gas composition can be set at constant values; however this assumption may not represent the real situation in shale gas formations. Secondly, shale gas composition can be considered as a function of well-pad location and design, due to the fact that shale gas formations are highly heterogeneous. Lastly, shale gas composition can be function of well-pad location and design as well as well-pad age, as shale gas is made up of different components whose desorption is selective, such that some components are produced first and others later. Here, shale gas composition is expressed as function of the binary variable $\operatorname{WellDes}(d, w, \mathrm{t})$, as given in Equation Error! Reference source not found.. The parameter $\operatorname{Comp}\left(i, d, w, t^{\prime}\right)$ represents the composition of component $i$ associated with design $d$ for well-pad $w$ of age $t^{\prime}$. Equation Error! Reference source not found. is general and can represent any of the cases mentioned above. However, if shale gas composition is assumed to be constant everywhere and over time, then Equation Error! Reference source not found. is not needed due to the fact that shale gas composition becomes a known parameter.

Moreover, there is a particular case where even with variable gas composition the bilinear terms related to material balances in compressor stations can be avoided. That case happens when the supply chain model is forced to choose only one gas processing plant. In this case, estimation of component flows becomes more appropriate than the estimation of gas composition. Individual component flows from well-pads are estimated through Equation Error! Reference source not found., where the variable $\operatorname{Prod}(i, w, t)$ represents the production of shale gas component $i$ from well-pad $w$ during period $t$.

$$
\operatorname{CompW}(i, w, t)=\sum_{t^{\prime} \leq t-1} \sum_{d} \operatorname{Comp}\left(i, d, w, t^{\prime}\right) * W \operatorname{WellDes}\left(d, w, t-t^{\prime}\right) \quad \forall i, w, t
$$


381

382

383

384

385

386

387

388

389

390

391

392

393

394

395

396

397

398

399

400

401

$\operatorname{Prod}(i, w, t)=\sum_{t^{\prime} \leq t-1} \sum_{d} \operatorname{Comp}\left(i, d, w, t^{\prime}\right) * W e l l G a s\left(d, w, t^{\prime}\right) * W e l l D e s\left(d, w, t-t^{\prime}\right) \quad \forall i, w, t$

\subsubsection{Water demand and specifications for hydraulic fracturing}

Water demand for hydraulic fracking $\operatorname{Wat} \operatorname{Dem}(d, w)$, which is a function of both design and well-pad location, can be supplied from freshwater resources and water treatment plants as expressed in Equation Error! Reference source not found.. Flow rates from freshwater sources and water treatment plants are represented by variables Flow $F W(f, w, t)$ and $F l o w H W(h, w, t)$, respectively. The link between water treatment plants and potential well-pads is defined by the set $l h w$. In addition, in order to avoid scaling and other issues, treated water and fresh water blends for hydraulic fracturing have to meet the specification regarding TDS concentration, as expressed in Equation Error! Reference source not found.. Parameters $T D S f(f)$ and $T D S h(h)$ represent the TDS concentration in water stream from freshwater sources and water treatment plants, respectively. In addition, parameter MaxTDS represents the maximum allowed TDS concentration in the water blend. This specification could be a function of well-pad location, in which case the parameter MaxTDS must be indexed by well-pad location $w$ $(\operatorname{MaxTDS}(w))$. It is important to note that there could be additional specifications imposed on the water blend, for instant maximum allowed concentration of hardness ions like Calcium, Chlorides, Barium and Strontium. In this case equations similar to Equation Error! Reference source not found. should be included for those additional requirements on water blend quality.

$$
\begin{aligned}
\sum_{f \mid(f, w) \in l f w} \operatorname{Flow} F W(f, w, t)+\sum_{h \mid(h, w) \in l h w} \operatorname{FlowHW}(h, w, t) \\
=\sum_{d} \operatorname{WatDem}(d, w) * W \operatorname{WellDes}(d, w, t) \quad \forall w, t
\end{aligned}
$$

$$
\begin{aligned}
& \sum_{f \mid(f, w) \in l f w} \operatorname{TDS} f(f) * \operatorname{Flow} F W(f, w, t)+\sum_{h \mid(h, w) \in l h w} \operatorname{TDSh}(h) * \operatorname{FlowHW}(h, w, t) \\
& \leq \operatorname{MaxTDS} * \sum_{d} \sum_{t^{\prime} \leq t-1} \operatorname{WellWate}\left(d, w, t^{\prime}\right) * \operatorname{WellDes}\left(d, w, t-t^{\prime}\right) \quad \forall w, t
\end{aligned}
$$


403

404

405

406

407

408

409

410

411

412

413

414

415

416

417

418

419

420

421

422

423

424

425

426

427

\subsubsection{Water production}

Water production profiles, flowback plus produced water, are calculated using Equation Error! Reference source not found.. The parameter WellWate $\left(d, w, t^{\prime}\right)$ represents the water production flow rate associated with design $d$ for well-pad $w$ of age $t^{\prime}$. This parameter includes the flowback water after a fracturing process and the produced water inherent to the shale formation. The water production balance is described in Equation Error! Reference source not found.. The variable $F l o w W H(w, h, t)$ represents the water flowrate from well-pad $w$ to treatment plant $h$ during period $t$. Likewise, variable FlowWS $(w, s, t)$ represents the water flowrate from well-pad $w$ to disposal site $s$ during period $t$. The linkage between well-pads and disposal sites is defined by the set lws.

$$
\operatorname{WateProd}(w, t)=\sum_{d} \sum_{t^{\prime} \leq t-1} \operatorname{WellWate}\left(d, w, t^{\prime}\right) * \operatorname{WellDes}\left(d, w, t-t^{\prime}\right) \quad \forall w, t
$$

$$
\operatorname{WateProd}(w, t)=\sum_{h \mid(h, w) \in l h w} \operatorname{FlowWH}(w, h, t)+\sum_{s \mid(w, s) \in l w s} \operatorname{FlowWS}(w, s, t) \quad \forall w, t
$$

\subsubsection{Water transportation cost}

The cost of transporting water from well-pads to water treatment plants and disposal sites is estimated through Equations Error! Reference source not found. and Error! Reference source not found., respectively. Unit transportation cost for water from well-pads to water treatment plants and disposal sites are defined in parameters $\operatorname{CostWateh}(w, h)$ and $\operatorname{CostWates}(w, s)$.

$$
\operatorname{CostWH}(t)=\sum_{w} \sum_{h \mid(h, w) \in l h w} \operatorname{CostWateh}(w, h) * \operatorname{FlowWH}(w, h, t) \quad \forall t
$$

$$
\operatorname{CostWS}(t)=\sum_{w} \sum_{s \mid(w, s) \in l w s} \operatorname{CostWates}(w, s) * \operatorname{FlowWS}(w, s, t) \quad \forall t
$$

\subsubsection{Capital and operating expenditures}

Capital expenditures CapexWE(t) associated with well-pads are estimated as stated in Equation Error! Reference source not found., where parameter CapexWell $(d, w)$ represents the capital expenditures associated with the implementation of design $d$ in wellpad $w$. In addition, operating expenditures OpexWE $(t)$ are calculated as defined in Equation 
Error! Reference source not found.. Here, the parameter OpexWell(w) represents the operating expenditure for well-pad $w$.

$$
\operatorname{CapexWE}(t)=\sum_{w} \sum_{d} \operatorname{CapexWell}(d, w) * \operatorname{WellDes}(d, w, t) \quad \forall t
$$

$$
\operatorname{OpexWE}(t)=\sum_{w} \operatorname{OpexWell}(w) * \operatorname{ShalProd}(w, t) \quad \forall t
$$

\subsection{Gas pipelines and compressor stations for raw gas transportation}

Pipelines and compressor stations are required in order to allow the transportation of raw gas from well-pads to gas plants. Different capacities can be selected for both pipelines and compressor stations, depending on the amount of gas to be transported and the distances between well-pads and gas plants. In this work, the gas pipelines and compressor stations are not modeled using compressive flow equations. Instead, we design the potential pipeline network based on fixed pressures at each node and using a process simulator to estimate capital and operating cost for different pipeline or compressor capacities. It is important to note that, for pipes, each capacity corresponds to a specific commercial size depending on the length of the pipe as well as the pressure drop between the inlet and output nodes.

\subsubsection{Gas pipeline capacity: Well-pad to compressor stations}

The capacity of a gas pipeline, for a given time period, is equal to the cumulative capacity expansion from the first period until period $t^{\prime}-t_{d}$, as stated in Equation Error! Reference source not found.. Scalar $t_{d}$ represents the lead time for gas pipeline construction. Capacity expansions can take discrete sizes only, which are defined by parameter $\operatorname{Sizep}(q)$. The binary variable $\operatorname{InstPwc}\left(q, w, c, t^{\prime}-t_{d}\right)$ is equal to one if a capacity expansion of size $q$ is assigned to gas pipeline from well-pad $w$ to compressor station $c$ during period $t$, the binary variable is equal to zero otherwise. Set $v$ defines all of the possible sizes for gas pipelines. Equation Error! Reference source not found. is used to guarantee that up to one size is selected for capacity expansions of a specific gas pipeline from well-pads to compressor stations during a given time period. 


$$
\operatorname{Flow} W C(w, c, t) \leq \sum_{t^{\prime} \leq t} \sum_{q \in v} \operatorname{Sizep}(q) * \operatorname{InstPwc}\left(q, w, c, t^{\prime}-t_{d}\right) \quad \forall(w, c) \mid(w, c) \in \operatorname{lwc}, t
$$

$$
\sum_{q \in \mathcal{v}} \operatorname{InstPwc}(q, w, c, t) \leq 1 \quad \forall(w, c) \mid(w, c) \in l w c, t
$$

457

458

459

460

461

462

463

464

465

466

467

468

469

470

471

472

473

\subsubsection{Material balance for compressor stations}

The gas flow balances in compressor stations are expressed in Equation

Error! Reference source not found.. The connections between compressor station and gas plants are defined by the set $l c p$. Additionally, set lcc contains the linkage between compression stations. The variables $\operatorname{FlowCC}\left(c, c^{\prime}, t\right)$ and $\operatorname{Flow} C P(c, p, t)$ represent the gas flow rate transported between compressor stations and from compressor stations to gas plants, respectively. Outlet stream compositions for compressor stations $\operatorname{CompC}(i, c, t)$ are estimated from Equation Error! Reference source not found., which is bilinear. It is important to note that if the composition of shale gas at well-pads is considered constant or if only one gas plant is allowed to be installed, the Equation Error! Reference source not found. is not needed and can be removed from the model formulation. In the first case of constant gas composition, the compressor outlet stream compositions become a known parameter equal to gas composition at well-pad locations. In the second case, where only one gas plant is allowed to be installed, individual component flows are used instead of gas composition.

$$
\begin{gathered}
\sum_{p \mid(c, p) \in l c p} F \operatorname{Flow} C P(c, p, t)+\sum_{c^{\prime} \mid\left(c, c^{\prime}\right) \in l c c} \operatorname{FlowCC}\left(c, c^{\prime}, t\right)=\sum_{w \mid(w, c) \in l w c} F \operatorname{FlowWC}(w, c, t) \\
+\sum_{c^{\prime} \mid\left(c^{\prime}, c\right) \in l c c} \operatorname{Flow} C C\left(c^{\prime}, c, t\right) \forall c, t
\end{gathered}
$$

$$
\begin{aligned}
\operatorname{CompC}(i, c, t) & *\left(\sum_{p \mid(c, p) \in l c p} \operatorname{FlowCP}(c, p, t)\right. \\
& \left.+\sum_{c^{\prime} \mid\left(c, c^{\prime}\right) \in l c c} \operatorname{Flow} C C\left(c, c^{\prime}, t\right)\right)=\sum_{w \mid(w, c) \in l w c} \operatorname{Comp} W(i, w, t) * \operatorname{Flow} W C(w, c, t) \\
& +\sum_{c^{\prime} \mid\left(c^{\prime}, c\right) \in l c c} \operatorname{Comp} C\left(i, c^{\prime}, t\right) * \operatorname{Flow} C C\left(c^{\prime}, c, t\right) \forall i, c, t
\end{aligned}
$$




\subsubsection{Capacity for compressor stations}

Constraints on the maximum capacity for compressor stations are defined in Equation Error! Reference source not found., using a similar approach to that in the gas pipeline case. The parameter $\operatorname{Sizec}(m)$ defines the potential capacities for the expansion of compressor stations. Additionally, the binary variable $\operatorname{InstC}(m, c, t)$ is equal to one if a capacity expansion of size $m$ is assigned to compressor station $c$ during period $t$, the binary variable is equal to zero otherwise. Equation Error! Reference source not found. is used to guarantee that up to one size is selected for capacity expansions of compressor stations during a given time period.

$$
\begin{aligned}
\sum_{p \mid(c, p) \in l c p} \operatorname{Flow} C P(c, p, t) & \\
+ & \sum_{c^{\prime} \mid\left(c, c^{\prime}\right) \in l c c} \operatorname{Flow} C C\left(c, c^{\prime}, t\right)=\sum_{t \prime \leq t} \sum_{m} \operatorname{Sizec}(m) * \operatorname{InstC}\left(m, c, t^{\prime}-t_{c}\right) \forall c, t
\end{aligned}
$$

$$
\sum_{m} \operatorname{InstC}(m, c, t) \leq 1 \quad \forall c, t
$$

\subsubsection{Gas pipeline capacity: Between compressor stations}

Analogous to capacity constraints for gas pipelines from well-pads to compressor station, capacity for gas pipelines between compressors is defined in Equation Error! Reference source not found.. Here, the binary variable $\operatorname{InstPcc}\left(q, c, c^{\prime}, t\right)$ is equal to one if a capacity expansion of size $q$ is assigned to gas pipeline from compressor station $c$ to compressor station $c^{\prime}$ during period $t$, the binary variable is equal to zero otherwise. Equation Error! Reference source not found. guarantees that up to one size is selected for capacity expansions of gas pipelines between compressor stations in a single period.

$$
\operatorname{FlowCC}\left(c, c^{\prime}, t\right) \leq \sum_{t^{\prime} \leq t} \sum_{q \in \mathcal{v}} \operatorname{Sizep}(q) * \operatorname{InstPcc}\left(q, c, c^{\prime}, t^{\prime}-t_{d}\right) \forall\left(c, c^{\prime}\right) \mid\left(c, c^{\prime}\right) \in l c c, t
$$

$$
\sum_{q \in v} \operatorname{InstP} P c\left(q, c, c^{\prime}, t\right) \leq 1 \quad \forall\left(c, c^{\prime}\right) \mid\left(c, c^{\prime}\right) \in l c c, t
$$


505

506

507

508

509

510

\subsubsection{Gas pipeline capacity: Compressor stations to gas plants}

The maximum capacity for gas pipelines between compressor stations and gas plants is defined in Equation Error! Reference source not found.. The binary variable $\operatorname{InstPcp}(q, c, p, t)$ is equal to one if a capacity expansion of size $q$ is assigned to gas pipeline from compressor station $c$ to gas plant $p$ during period $t$; the binary variable is equal to zero otherwise. Equation Error! Reference source not found. guarantees that up to one size is selected for capacity expansions of gas pipelines from compressor stations to gas plants in a single period.

$$
\operatorname{Flow} C P(c, p, t) \leq \sum_{t^{\prime} \leq t} \sum_{q \in v} \operatorname{Sizep}(q) * \operatorname{InstPcp}\left(q, c, p, t^{\prime}-t_{d}\right) \quad \forall(c, p) \mid(c, p) \in l c p, t
$$

$$
\sum_{q \in v} \operatorname{InstPcp}(q, c, p, t) \leq 1 \quad \forall(c, p) \mid(c, p) \in l c p, t
$$

\subsubsection{Gas pipeline capacities: Well-pads to gas plants}

The capacity constraint for gas pipelines from well-pads to gas plants is expressed in Equation Error! Reference source not found.. The binary variable $\operatorname{InstP} w p(q, w, p, t)$ is equal to one if a capacity expansion of size $q$ is assigned to gas pipeline from well-pad $w$ to gas plant $p$ during period $t$; the binary variable is equal to zero otherwise. Equation Error! Reference source not found. guarantees that up to one size is selected for capacity expansions of gas pipelines between well-pads and gas plants in a single period.

$$
F l o w W P(w, p, t) \leq \sum_{t^{\prime} \leq t} \sum_{q \in v} \operatorname{Sizep}(q) * \operatorname{InstPwp}\left(q, w, p, t^{\prime}-t_{d}\right) \quad \forall(w, p) \mid(w, p) \in l w p, t
$$

$$
\sum_{q \in v} \operatorname{InstPwp}(q, w, p, t) \leq 1 \quad \forall(w, p) \mid(w, p) \in l w p, t
$$

\subsubsection{Capital and operating expenditures}

Capital expenditures for new gas pipelines are calculated using Equation Error! Reference source not found.. Parameters $\operatorname{CapexP} w c(w, c, q)$ and $\operatorname{CapexP} w p(w, p, q)$ are related to capital expenditures for gas pipelines from well-pads to compressor stations and from well-pads to gas plants, respectively. Similarly, parameters $\operatorname{CapexPcc}\left(c, c^{\prime}, q\right)$ and 
CapexPcp $(c, p, q)$ are related to capital expenditures for gas pipelines between compressor stations and from compressor stations to gas plants, respectively. Capital expenditures for compressor stations are estimated using Equation Error! Reference source not found., where parameter $\operatorname{Capex} \operatorname{Com}(m, c)$ represents the Capex for compressor stations as function of their capacities. In addition, operating expenditures for compressor stations are estimated in terms of total output gas flow, as stated in Equation Error! Reference source not found.. The parameter OpexCom(c) is defined as the unit operating expenditures for compressor stations.

$$
\begin{aligned}
& \operatorname{CapexPI}(t)=\sum_{w} \sum_{c \mid(w, c) \in l w c} \sum_{q \in v} \operatorname{CapexPwc}(w, c, q) * \operatorname{InstPwc}(q, w, c, t) \\
& +\sum_{w} \sum_{p \mid(w, p) \in l w p} \sum_{q \in v} \operatorname{CapexPwp}(w, p, q) * \operatorname{InstP} w p(q, w, p, t) \\
& +\sum_{c}^{w} \sum_{c^{\prime} \mid\left(c, c^{\prime}\right) \in l c c} \sum_{q \in v} \operatorname{CapexPcc}\left(c, c^{\prime}, q\right) * \operatorname{InstPcc}\left(q, c, c^{\prime}, t\right) \\
& +\sum_{c} \sum_{p \mid(c, p) \in l c p} \sum_{q \in v} \operatorname{CapexPcp}(c, p, q) * \operatorname{InstP} c p(q, c, p, t) \forall t
\end{aligned}
$$

$$
\operatorname{CapexCO}(t)=\sum_{c} \sum_{m} \operatorname{Capex} \operatorname{Com}(m, c) * \operatorname{InstC}(m, c, t) \forall t
$$

$$
\begin{aligned}
\operatorname{OpexCO}(t)= & \sum_{c} \operatorname{OpexCom}(c) \\
& *\left(\sum_{c \prime^{\prime}\left(c, c^{\prime}\right) \in l c c} \operatorname{Flow} C C\left(c, c^{\prime}, t\right)+\sum_{p \mid(c, p) \in l c p} \operatorname{Flow} C P(c, p, t)\right) \forall t
\end{aligned}
$$

\subsection{Wastewater treatment plants}

Wastewater recovered from well-pads can be treated in water plants to meet quality requirements either for re-use or recycling. Moreover, wastewater and treated water can be stored in tanks located in water plants in order to be treated or used when needed. The corresponding layout of the water treatment process is presented in Figure 3.

\subsubsection{Maximum treatment capacity and specifications for wastewater}

The amount of wastewater that can be processed by a plant, WateProc $(h, t)$, is limited by the water plant capacity which is equal to the cumulative capacity expansion 
from the first period until period $t^{\prime}-t_{h}$; this constraint is defined in Equation Error! Reference source not found.. The parameter Sizeh(k) represents the potential sizes for capacity expansions of water treatment plants. The scalar $t_{h}$ represents the lead time for water treatment plant construction. The binary variable $\operatorname{Inst} H(k, h, t)$ is equal to one if a capacity expansion of size $k$ is assigned to plant $h$ during period $t$, the binary variable is equal to zero otherwise. Equation Error! Reference source not found. ensures that no more than one size is assigned to capacity expansions of a specific plant in a given time period.

$$
\text { WateProc }(h, t) \leq \sum_{t^{\prime} \leq t} \sum_{k} \operatorname{Sizeh}(k) * \operatorname{Inst} H\left(k, h, t^{\prime}-t_{h}\right) \forall h, t
$$

$$
\sum_{k} \operatorname{InstH}(k, h, t) \leq 1 \quad \forall h, t
$$

Likewise, wastewater has to meet some specifications (i.e maximum TDS concentration) in order to be treated by a specific treatment plant, depending on its technology (i.e. distillation, crystallization, and reverse osmosis). In order to simplify the mathematical formulation to be linear, the restriction on the maximum TDS concentration treatable by a certain technology is imposed before the input tank shown in Figure 3. This is modeled by the Equation Error! Reference source not found. that accounts for the specification on the maximum TDS concentration on wastewater. The parameters $T D S w(w)$ and $\operatorname{MaxTDSt}(h)$ represent the TDS concentration in wastewater from each well-pad and the maximum TDS concentration that each treatment plant can handle, respectively. In this formulation only the specification for TDS concentration is considered. However, the formulation can be easily extended to account for the treatment of additional contaminants.

$\sum_{w \mid(h, w) \in l h w} \operatorname{TDSw}(w) * \operatorname{FlowWH}(w, h, t) \leq \operatorname{MaxTDSt}(h) * \sum_{w \mid(h, w) \in l h w} \operatorname{FlowWH}(w, h, t) \forall h, t$

It is worth mentioning that although the linear version of the maximum TDS constraint is an approximation, it ensures that the technical limitations of a plant operating 
with a certain technology are still valid. If a more general formulation is required, then Equation Error! Reference source not found. should be replaced by Equations Error! Reference source not found. and Error! Reference source not found.. In this case, the variable $\operatorname{TDS}(h, t)$ is introduced to account for the TDS concentration in the input tank, which is equal to the TDS concentration in the stream WateProc $(h, t)$. The material balance for the input tank is presented in Equation Error! Reference source not found.. The right and left-hand side of this equation introduces a nonlinearity due to the product of the TDS concentration and the variables $\operatorname{RawTank}(h, t)$ and $\operatorname{WateProc}(h, t)$. The maximum TDS concentration that can be processed by a plant is expressed by the Equation Error! Reference source not found.. The variable $\operatorname{RawTank}(h, t)$ refers to the quantity of water stored in inlet tank associated with water plant $h$ in period $t$.

$$
\begin{gathered}
\sum_{w \mid(h, w) \in l h w} \operatorname{TDSw}(w) * \operatorname{FlowWH}(w, h, t)+\operatorname{TDS}(h, t-1) * \operatorname{RawTank}(h, t-1) \\
\leq \operatorname{TDS}(h, t) *(\operatorname{RawTank}(h, t)+\operatorname{WateProc}(h, t)) \forall h, t
\end{gathered}
$$

$$
\operatorname{TDS}(h, t) \leq \operatorname{MaxTDS}(h) \forall h, t
$$

\subsubsection{Material balance}

Tanks for storage of wastewater are included in the formulation as an optional step before the water treatment process. The corresponding material balance is presented in Equation Error! Reference source not found.. The storage of wastewater is limited by the maximum capacity of a tank, $\operatorname{Raw} \operatorname{Cap}(k)$, and conditioned on the availability of a water plant represented by the binary variable $\operatorname{Inst} H\left(k, h, t^{\prime}-t_{h}\right)$; this is modelled by means of equation Error! Reference source not found.. The material balance across water plants is described in Equation Error! Reference source not found., where set lhs defines the linkage between water treatment plants and disposal sites. The variable $\operatorname{FlowHS}(h, s, t)$ defines the flow rate of treated water from plant $h$ to disposal site $s$ during period $t$. The water recovery factor for each water treatment plant is defined by the parameter $\psi(h)$. In addition, variable WateTank $(h, t)$ is defined as the volume of treated water that remains in the storage tank associated with plant $h$ at the end of period $t$. Since storage tanks have 
591

592

593

594

595

596

597

598

599

600

601

602

603

604

605

606

607

finite capacities, Equation Error! Reference source not found. guarantees that water storage capacities are not exceeded. The parameter $\operatorname{TankCap}(k)$ represents the potential capacities for expansions of storage tanks in water plants.

$\sum_{w \mid(h, w) \in l h w} \operatorname{FlowWH}(w, h, t)+\operatorname{RawTank}(h, t-1)=\operatorname{WateProc}(h, t)+\operatorname{RawTank}(h, t) \forall h, t$

$$
\operatorname{RawTank}(h, t)=\sum_{t^{\prime} \leq t} \sum_{k} \operatorname{RawCap}(k) * \operatorname{InstH}\left(k, h, t^{\prime}-t_{h}\right) \forall h, t
$$

$$
\begin{aligned}
& \psi(h) * \text { WateProc }(h, t)+\text { WateTank }(h, t-1) \\
& =\sum_{w \mid(h, w) \in l h w} F \operatorname{FlowWH}(h, w, t)+\sum_{s \mid(h, s) \in l h s} \operatorname{FlowHS}(h, s, t) \\
& + \text { WateTank }(h, t) \forall h, t
\end{aligned}
$$

$$
\operatorname{WateTank}(h, t) \leq \sum_{t \prime \leq t} \sum_{k} \operatorname{Tank} \operatorname{Cap}(k) * \operatorname{InstH}\left(k, h, t^{\prime}-t_{h}\right) \forall h, t
$$

\subsubsection{Treated water transportation costs}

The costs related to water transportation from water treatment plants to well-pads are estimated using Equation (52). The parameter $\operatorname{CostRech}(h, w)$ represents the unit transportation cost for treated water from plant $h$ to well-pad $w$. Moreover, the cost related to water transportation from water treatment plants to disposal sites is given by Equation (53), where the parameter $\operatorname{CostRecs}(h, s)$ represents the unit transportation cost for treated water from treatment water plants to disposal sites.

$$
\operatorname{CostHW}(t)=\sum_{h} \sum_{w \mid(h, w) \in l h w} \operatorname{CostRech}(h, w) * \operatorname{FlowHW}(h, w, t) \quad \forall t
$$




\subsubsection{Capital and operating expenditures}

Capital expenditures associated with the installation of new water treatment plants are estimated using Equation (54). The parameter CapexWate $(k, h)$ defines the capital cost for potential capacities of water treatment plants. Operating expenditures are estimated as described in Equation (55), where the parameter OpexWate $(h)$ represents the operating cost associated to plant $h$.

$$
\begin{gathered}
\text { CapexWA }(t)=\sum_{h} \sum_{k} \text { CapexWate }(k, h) * \operatorname{InstH}(h, t) \quad \forall t \\
\text { OpexWA }(t)=\sum_{h} \text { OpexWate }(h) * \sum_{w(h, w) \in \operatorname{lhw}} \operatorname{FlowWH}(w, h, t) \quad \forall t
\end{gathered}
$$

\subsection{Gas treatment plants}

In order to deliver gas and liquid products to final customers, the raw gas needs to be treated and separated in gas processing plants.

\subsubsection{Processing capacity}

The gas processing capacity is defined as the cumulative capacity expansion from the first period until period $t-t_{g}$, as expressed in capacity constraint defined in Equation (56). The parameter Sizeg $(g)$ defines the potential capacities for installation and expansion of gas plant. The scalar $t_{g}$ accounts for the lead-time for construction of gas plants. The binary variable $\operatorname{Inst} G(g, p, t)$ is equal to one if a capacity expansion of size $g$ is assigned to plant $p$ during period $t$, the binary variable is equal to zero otherwise. Equation (57) ensures that capacity expansions take only one size at a time. If the supply chain model is forced to choose only one gas processing plant, Equations (58) and (59) should be added to the mathematical formulation. Binary variable PlanSite $(p)$ is equal to 1 is a gas processing plant $p$ is selected: the binary variable is equal zero otherwise. Additionally, the scalar MaxExp denotes the maximum number of expansions that is allowed for gas processing plants. 
633

634

635

636

637

638

639

640

641

642

643

644

645

646

647

648

649

650

651

652

$$
\begin{aligned}
\sum_{w \mid(w, p) \in l w p} & \text { FlowWP }(w, p, t)+\sum_{c \mid c, p) \in l c p} \text { FlowCP }(c, p, t) \leq \\
& \quad \sum_{t^{\prime} \leq t} \sum_{g} \operatorname{Sizeg}(g) * \operatorname{Inst} G\left(g, p, t^{\prime}-t_{g}\right) \quad \forall p, t
\end{aligned}
$$

\subsubsection{Material balance}

The material balance for gas plants is given by Equation (60). As defined in previous sections, terms $\operatorname{Comp} W(i, w, t)$ and $\operatorname{Comp} C(i, c, t)$ are related to the composition of shale gas streams from well-pads and compressor stations, respectively. These terms can be constants in the case that shale gas composition is considered to be constant everywhere and over the planning time. Nevertheless, in the general case these terms will be variable and thus Equation (60) becomes bilinear. The parameter $\phi(i, p)$ accounts for the separation efficiency in gas plants. The linkage between gas components and demand centers is defined by the set lij. The variable $\operatorname{FlowPJ}(p, i, j, t)$ denotes the flow rate of component $i$ from gas plant $p$ to demand center $j$ during period $t$. If only one gas plant is allowed to be installed, then the material balance across the gas plants is reduced to Equation (61), which is linear.

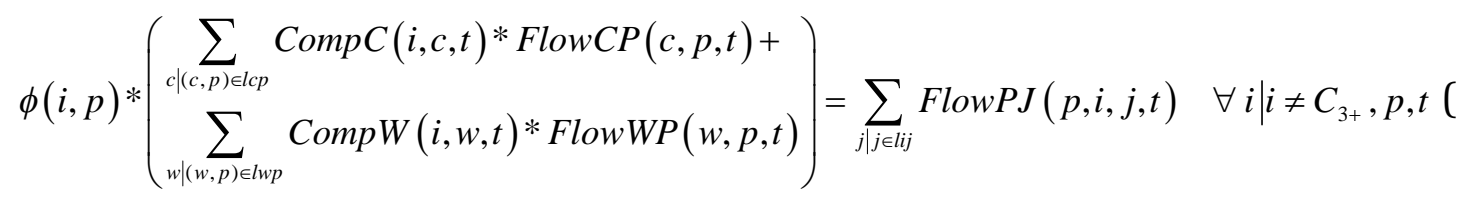


653

654

655

656

657

658

659

660

661

662

663

664

665

666

667

668

669

670

671

$$
\operatorname{OpexGA}(t)=\sum_{p} \operatorname{OpexGas}(p) *\left(\sum_{w \mid(w, p) \in l w p} \operatorname{Flow} W P(w, p, t)+\sum_{c \mid(c, p) \in l c p} \operatorname{Flow} C P(c, p, t)\right) \forall t
$$

\subsubsection{Income from selling $\mathrm{C}_{3+}$ at gas processing plant locations}

As was mentioned before, $\mathrm{C}_{3+}$ hydrocarbons are assumed to be sold at gas processing plant locations. Equations (62) and (63) are used to calculate the revenue from selling $\mathrm{C}_{3+}$ hydrocarbons for the general case (variable composition) and the case with only one gas processing plant, respectively. The parameter PriceC3 $(p, t)$ represents the prices of $\mathrm{C}_{3+}$ hydrocarbons at gas processing plant $p$ during period $t$.

ReveC $3(t)=$

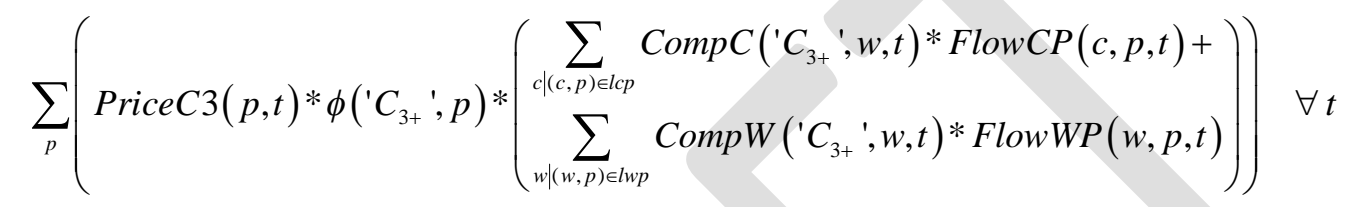

\subsubsection{Capital and operating expenditures}

Capital and operating expenditures for gas processing plants are estimated using Equations (64) and (65), respectively. The parameter CapexGas $(g, p)$ represents capital investment for potential capacities of gas plants. Similarly, parameter OpexGas $(p)$ represents the unit operating expenditures for gas plants.

$$
\operatorname{CapexGA}(t)=\sum_{p} \sum_{g} \operatorname{CapexGas}(g, p) * \operatorname{Inst} G(p, t) \quad \forall t
$$


674

675

676

677

678

679

680

681

682

683

684

685

686

687

688

689

690

691

692

693

694

695

696

697

698

\subsection{Product pipelines and Demand centers}

Final products can be transported to demand centers through either gas or liquid pipelines, depending on the nature of the final product that is required.

\subsubsection{Capacity for product pipelines between gas plants and demand centers}

Capacity constraint for gas pipelines between gas plants and demand centers is defined in Equation (66). Similarly, Equation (67) defines the capacity constraint for liquid pipelines between gas plants and demand centers. Equation (68) is used to guarantee that no more than one size is selected for capacity expansions of a specific pipeline from gas plants to demand centers during a given time period. The parameter $\operatorname{Sizepl}(u)$ defines potential sizes for liquid pipelines, where set $u$ defines the sizes available for liquid pipelines. The variable $\operatorname{InstPpj}(q, p, j, t)$ is equal to one if a capacity expansion of size $q$ is assigned to gas pipeline from gas plant $p$ to demand center $j$ during period $t$, the binary variable is equal to zero otherwise. Demand centers associated to gas products are defined by set $j g$, while demand centers associated with liquid products are defined by set $j l$. It is assumed here that each demand center is associated with only one product.

$$
\sum_{i \mid(i, j) \in l i j} \operatorname{FlowPJ}(p, i, j, t) \leq \sum_{t^{\prime} \leq t} \sum_{q \in v} \operatorname{Sizep}(q) * \operatorname{InstPpj}\left(q, p, j, t^{\prime}-t_{d}\right) \quad \forall p, j \mid j \in j g, t
$$

$$
\sum_{i(i, j) \in l i j} \operatorname{FlowPJ}(p, i, j, t) \leq \sum_{t^{\prime} \leq t} \sum_{q \in u} \operatorname{Sizepl}(q) * \operatorname{InstPpj}\left(q, p, j, t^{\prime}-t_{d}\right) \quad \forall p, j \mid j \in j l, t
$$

$$
\sum_{q} \operatorname{InstPpj}(q, p, j, t) \leq 1 \quad \forall p, j, t
$$

\subsubsection{Capital expenditures and final product demands}

Capital expenditures for pipelines transporting final products are estimated from Equation (69). The parameter $\operatorname{CapexPpj}(p, j, q)$ represents capital investment for product pipelines. Equation (70) ensures that final product flows do not exceed maximum demand for final products in any demand center during each time period. Product demand is denoted by the parameter $\operatorname{Dem}(j, t)$.

$$
\operatorname{CapexPJ}(t)=\sum_{p} \sum_{j} \sum_{q} \operatorname{CapexPpj}(p, j, q) * \operatorname{InstPpj}(q, p, j, t) \quad \forall t
$$


701

702

\subsection{Disposal sites}

There are different types of water disposal sites, for instance, rivers and injection sites. Each disposal site can have limitations in terms of capacity, as stated in Equation (71). The parameter CapDis $(s, t)$ represents the capacities for disposal sites. In addition, some of those disposal sites can entail operating expenditures, as is the case for underground injection sites. Operating expenditures for disposal sites are estimated by using Equation (72), where operating cost are represented by parameter OpexDis $(s)$. It is important to clarify that, only certain water treatment plants can discharge water into rivers, this depends on their technology and on the water quality constraints for disposal established by local regulations.

$$
\begin{gathered}
\sum_{w \mid w \in l w s} \operatorname{FlowWS}(w, s, t)+\sum_{h \mid h \in l h s} \operatorname{FlowHS}(h, s, t) \leq \operatorname{CapDis}(s, t) \quad \forall s, t \\
\operatorname{OpexDI}(t)=\sum_{s} \operatorname{OpexDis}(s) *\left(\sum_{w \mid w \in l w s} \operatorname{FlowWS}(w, s, t)+\sum_{h \mid h \in l h s} \operatorname{FlowHS}(h, s, t)\right) \forall t
\end{gathered}
$$

\subsection{Model summary}

There are two particular cases where the shale gas supply chain optimization model described above becomes a Mixed Integer Programming (MILP) problem. First, when shale gas composition is considered constant across the shale formation and over the planning time, then the bilinear terms associated with the estimation of compositions in the outlet stream of the compressors are not required in the model formulation. Therefore, the optimization model becomes MILP. Secondly, in the case where no more than one gas processing plant is allowed, the estimation of the output compositions in the compressors is not necessary. Instead, component flows are used in the material balances associated with the gas processing units. Consequently, despite of the fact that the gas composition could be variable, the optimization model will remain as a MILP. 
It was pointed out in the previous sections, that the shale gas composition could depend on well-pad location and/or well-pad age. In this case, the shale gas composition in outlet streams from well-pads and compressor stations are variables. Additionally, the TDS concentration on wastewater can vary not only spatially but also temporally. In this case, TDS concentration associated with wastewater from well-pads is a variable rather than a parameter. In other words, parameter $\operatorname{TDS} w(w)$ becomes variable $T D S w(w, t)$, which can be estimated as function of the binary variable $\operatorname{WellDes}(d, w, t)$ using an expression similar to equation Error! Reference source not found.. In the general case, the model would be classified as a Mixed Integer Nonlinear Programming (MINLP) problem given that bilinear terms are present in the mathematical model. These bilinear terms, which are nonconvex, are due to the product of two continuous variables, flow rates and either gas composition or TDS concentration. Therefore, the model can be classified as a Mixed Integer Bilinear Programing problem, which is a subclass of Mixed Integer Quadratically Constrained Programing (MIQCP) problems. These types of optimization problems can be transformed into a MILP problem by the convexification of bilinear products, for instance, through convex hull approximation of the bilinear terms (McCormick 1976; Sherali and Adams 1994; Wicaksono and Karimi 2008; Castro 2015). The solution to this sub-problem provides an upper bound to the original MIQCP problem and an iterative solution approach is needed in order to get a solution close enough to the global optima. Although solvers like DICOPT (Duran and Grossmann 1986) and SBB (Bussieck and Drud 2001) can be used to solve the original MIQCP problem, those solvers can lead to local optimal solutions in most cases. Finally, global optimization solvers like ANTIGONE (actually GloMIQO) (Misener and Floudas 2012, 2014), BARON (Tawarmalani and Sahinidis 2005; Sahinidis 2014), and LindoGlobal (Lin and Schrage 2009) can be used at the expense of high computational times. Since there is a trade-off between solution quality and computational cost, it is appropriate to test all those options in order to define the more effective approach to solve the MIQCP optimization problem. Finally, all of the possible models that can result from the mathematical formulation for shale gas supply chain optimization are summarized in Table 2. 
753

754

755

756

757

758

759

760

761

762

763

764

765

766

767

768

769

770

771

772

773

774

775

776

777

778

779

780

781

782

\section{Model implementation}

This section describes the implementation of the optimization framework proposed in this work. First, a workflow for the integration of the different components considered in the framework is presented. Then, the applicability of the proposed framework is demonstrated by its implementation in a case study in which the linear version of the model is implemented to optimize the shale gas supply chain for a shale formation where the gas composition is kept constant. A second case study is reported that illustrates the relevancy of the MIQCP model in which nonlinear TDS balance in water treatment plants are included and the gas composition changes across the shale formation and with time.

\subsection{Workflow}

Based on the description of shale gas supply chain problem presented in sections 2 and 3, we propose a workflow (see Figure 4) for the implementation of the optimization framework for the design and planning of the shale gas supply chain. The workflow merges three elements: Input data, optimization model, and output data. The input data refers to the infrastructure and parameters associated with the shale gas supply chain, market conditions, and water management. The input data is arranged in three different segments, as follows: (1) Reservoir simulation, which is a robust tool that allows the study of the influence of formation properties along with well-pad designs on production profiles. This component generates information regarding water demand, and gas and water production profiles for each well-pad design and location. (2) Transportation and processing units, which refers to the potential shale gas supply chain network, as well as capacity, Capex and Opex for each transportation and processing unit in the network. (3) Water resources availability, which requires the use of georeferenced data regarding water availability and quality at each potential fresh water source, potential water injection and disposal sites, and regional constraints on water management. The optimization model refers to any variant of the mathematical formulation presented in section 3 and summarized in Table 2 . The output data, derived from the solution of the optimization model, include information regarding the optimal drilling strategy, shale gas supply chain infrastructure, and the 
investment plan. Finally, in order to automate the implementation of the framework, the workflow was combined into an Excel-GAMS interface, where all the input data is in Excel, which is linked to a symbolic optimization model coded in GAMS. After solving the optimization model, the output data is sent back to Excel, where the analysis of the optimal solution is carried out.

\subsection{Case studies}

The following two case studies (A and B) illustrate some of the capabilities of the proposed optimization framework. The infrastructure for the case studies was specified based on the Middle Magdalena Valley Basin, which is a prospective shale play in Colombia. The case studies were developed following the workflow discussed in section 4.1. The infrastructure consists of 5 potential well-pads, 3 freshwater sources, 2 compressor stations ( 2 sizes each), 1 water treatment plants (3 sizes) with primary treatment technology, 1 water treatment plants ( 3 sizes) with secondary treatment technology, 2 gas processing plants (3 sizes), 1 injection site, 2 disposal sites, and 3 demand centers. The planning period has a 10 year time horizon divided into 40 quarters.

In this work, the design of the well-pads follows the methodology presented by the authors in Calderón et al. 2015, where 18 different well-pad designs or configurations were simulated on a widely used commercial software and their performance was addressed for the prospective shale play studied in this work. Two well-pads configurations were chosen with complementary economic and environmental performance. As an economic attractive well-pad design, we use a configuration composed by 14 wells, with a horizontal length of 9,000 ft and fracture stages spaced every $200 \mathrm{ft}$. This design is labeled as "MaxNPV". The second well-pad design is chosen based on environmental criteria in terms of minimum water intensity (gallons) per total gas production in energy units (MM Btu). This design, labeled as "MinWI", is composed by 6 wells, with a horizontal length of 5,000 ft and fracture stages spaced every $200 \mathrm{ft}$.

The potential transport and processing infrastructures for gas and water supply chains (see Figure 5) was generated using ArcGIS $^{\circledR} 10.2$ (ESRI 2014), which is a geographic 
information system. Five well-pads are connected either to a compression station or directly to the gas treatment facilities. The compressor stations 1 and 2 send the raw gas to gas treatment plants 1 and 2, respectively. A pipeline connecting the compressor 2 with the compressor 1 is added in order to allow the transportation of gas from the right-hand side of the area (see Figure 5) to the gas plant 1 in case the gas plant 2 is not installed. Similarly, a connection between compressor 1 and gas plant 2 is added to allow the transportation of gas produced by well-pads W1 and W4 to gas plant 2 in case the gas plant 1 is not installed. The final products are sent to the demand centers. In this case, we consider as demand centers three injection points located along the National pipeline network in Colombia. The methane fraction produced in gas plant 1 and 2, can be delivered to two different injection points in the southwest or southeast, respectively. These injection points are subsequently connected to several gas-based power plants. Only one common point placed in north of the shale play is included for ethane injection. This point is indirectly connected to a petrochemical plant. The prices of the final products were based on information from the Colombian Mining and Energy Planning Unit-UPME (http://www1.upme.gov.co/). The reported data indicate significant variations in the price of methane along the planning time. Initially, the methane price is set to 4,146 \$MMSCF. Although the price drops in some of the subsequent periods, in general it increases up to 8,293 \$/MMSCF in the last period. The variability in gas prices is driven by the dynamics of the local gas market. It has been forecast that Colombia will face a transition in gas supply, from a self-sufficient gas supply at the very beginning of the time horizon (the first three or four years) towards a scenario of net gas importer in the following years. This transition explains the higher gas prices in the last years of the time horizon, see Figure 6. The ethane price was set constant at 0.4762 \$/gallon, and an average price of $1.1 \$$ /gallon was used for $\mathrm{C}_{3+}$ products.

The potential infrastructure of the water supply chain was based on a road network connecting the different water sources with the demand points and the treatment facility locations. Three rivers supply fresh water for drilling and fracturing the well-pads. It is important to clarify that the cost of fresh water acquisition at the source is not considered here, i.e. there is no charge for fresh water sources, as according to the Colombian regulations, there is not extra charges for extraction of fresh water from rivers. This 
contrasts with the United States case where the regulation contemplates both usage charges and access charges (http://www.water.nsw.gov.au/water-management/fees-andcharges). The fresh water availability in rivers I, II and III were estimated based on hydrological balances carried out in ArcGIS. The hydrological balances incorporate historical data about precipitation, evapotranspiration, infiltration, and downstream demand as well as additional future downstream water demand. The results from the hydrological balances revealed a monomodal rainfall pattern in the region under study, with high precipitation in quarter 3 of each year. This phenomenon is reflected in the availability of fresh water resources. For the dry season, the first quarter of the year, the available water was estimated to be about $50 \%$ of the available water in the rainy season. For the second and fourth quarter, this percentage was set at $75 \%$. The total dissolved solids (TDS) concentration in water for the rivers I, II and III were set at 130, 150 and 140 $\mathrm{mg} / \mathrm{l}$, respectively. The TDS in the produced water was assumed to be different in each well-pad ranging between 34,300 and 106,700 mg/l. Well-pads W2 and W3 produce wastewater with TDS concentration of 34,335 and $36,671 \mathrm{mg} / \mathrm{L}$, respectively. This is a relatively good quality wastewater, since only primary treatment is required to treat this wastewater for re-use in future fracturing operations at other well-pad locations. On the other hand, well-pads W1, W4, and W5 produce wastewater with TDS concentration of $53,082,106,775$, and $79,765 \mathrm{mg} / \mathrm{L}$, respectively. This is a relatively poor quality wastewater. For instance, dilution with good quality wastewater is required for re-use treatment, which constraint the amount of wastewater from well-pads W1, W4, and W5 that can be treated. Alternatively, secondary treatment can be used in order to recycle wastewater from the aforementioned well-pads but water treatment cost will increase significantly. The wastewater from well-pad locations can be sent by truck to any of the two water treatment facilities. Alternatively, the wastewater can also be sent for deep injection into an adequate well located towards the north of the shale play. The treated water can be re-used or recycled and used for fracturing operations in new well-pads or discharged into rivers I and II. Water trucking is the only transportation mode considered, although additional modes can be included if necessary. As a reference, typical economic information related to the development of shale gas resources and its corresponding water management is presented in Table 3. Details regarding the estimation of capital and 
operational expenditures for gas and water transport and processing units as well as wastewater quality, i.e. TDS concentration, are presented in Table 4. The capital cost and operating cost for transporting and processing units were based on Aspen Hysys $₫$, Aspen Capital Cost Estimator $\AA$, and information from Colombian companies. Information regarding the local companies is not provided due to confidential agreements. The optimization problems were solved using GAMS 24.4.1. The MILP problem (Case Study A) was solved with CPLEX 12.6.1. Additionally, the MIQCP problem (Case Study B) was solved with ANTIGONE 1.1 (GloMIQO 2.3), using CPLEX 12.6.1 for solving MILP relaxations and CONOPT 3.16D as the nonlinear programming (NLP) solver. All runs were performed on a Dell OptiPlex 7010 with Intel ${ }^{\circledR}$ Core $^{\mathrm{TM}}$ i7-3770 CPU @3.40 GHz and 16 GB RAM running Windows $7^{\circledR}$ Enterprise (64-bit operating system). The optimality gap was set to less than or equal to $1 \%$ for all cases.

\subsubsection{Case Study A: Constant gas composition}

In Case Study A, the composition of the raw gas; composed of methane, ethane and heavier hydrocarbons $\left(\mathrm{C}_{3+}\right)$, is considered to be constant across the field. This case corresponds to a simplification of the general formulation, which consists of the equations associated with the "constant gas composition" case listed in Table 2. Therefore, the optimization problem solved in this case study corresponds to a MILP model. This model was solved to optimality with CEPLEX in $\sim 2.12$ minutes with a final optimality gap of about 1\%. The corresponding model statistics are summarized in Table 5. The optimal NPV was about $\$ 26.04$ million which corresponds to a net profit of 0.094 \$MMBtu. This margin is expected to increase as more potential well-pads are considered for the exploitation of the play. The values for Capex, Opex, royalties and taxes are discounted to the first period and the total cost breakdown is presented in Figure 7. Capex has a share of $71.9 \%$ of the total cost, followed by taxes with $14.3 \%$ and finally royalties and Opex with $8.1 \%$ and $5.6 \%$, respectively. These results reflect a well-known fact of the shale gas industry, in which the finances are dominated by the capital investment component in comparison to the operating costs. The breakeven gas price, defined here as the ratio between total 
expenditures (Capex plus Opex including water transportation cost) and total gas production, was found to be 4.08 / MMBtu.

In total, 3 well-pads were drilled and fractured with a MaxNPV design (well-pads W2, W3 and W5), and 2 well-pads were put in operation with a MinWI design (well-pads W1 and W4). In total, 54 wells were drilled and fractured during the planning horizon. The wastewater from the well-pads W2 and W3 has low TDS concentration below 50,000 mg/l, which allows higher water production, and therefore higher gas production, without affecting the technology selected for its treatment. The well-pad W4 produces wastewater with high TDS concentration around $107,000 \mathrm{mg} / \mathrm{L}$, so low wastewater production is desirable in order to reduce the cost of treatment and therefore a MinWI design was selected. In the case of well-pads W1 and W5, with TDS around 53,000 mg/L and 80,000 $\mathrm{mg} / \mathrm{L}$, respectively, this situation does not apply and it seems that the distance from the well-pads to the gas treatment facility, which is directly related to investment and operating cost of the gas transportation, is the determining factor. The corresponding drilling scheme of the selected designs is shown in Figure 8. The well-pad W2 is drilled first in period 11; then well-pads W3, W4 and W1 are drilled successively in periods 12, 13 and 14, respectively. Finally, the well-pad W5 is drilled in period 20. The total raw gas production per period and accumulative production are presented in Figure 9. The gas production initiates after period 11 and quickly reaches a peak of 198.6 MMSCFD in period 15. Next, the gas production decreases steadily for the next 5 periods; at this point the wellpad W5 is put in operation which is reflected in an increment of the global production up to 195.0 MSCFD. The cumulative production indicates that at the end of the planning horizon, a total of 278.0 BSCF of raw gas were produced. Accordingly, compressor 2, which is connected to well-pads W2 and W3, is installed in advance in period 8 with a capacity of 300 MMSCFD; in this example it is assumed that it takes 4 periods for a compressor to be installed. The production of well-pads W1 and W4 is sent to compressor 1 which is installed in period 11 with a capacity of 150 MMSCFD. The selection of the well-pad design has a direct impact on the chosen capacity required for both compressors. The reason for the delay of the drilling operations can be explained by the higher methane prices at the end of the time horizon, almost double of the initial price; thus the drilling schedule tends 
to take advantage of higher prices at later stages of the planning horizon. Regarding the gas treatment facilities, only gas plant 2 was installed in period 8 with a capacity of 200 MMSCFD; no further expansions were selected for this facility.

Both water treatment facilities were installed; water treatment plant 1, with primary treatment technology, was installed in period 7 and then expanded in period 8. The final capacity of this facility is 882,000 gal/day. Water treatment plant 2 , with secondary treatment technology, was installed in period 8 with a capacity of 441,000 gal/day; no subsequent expansions are carried out in this case. The water treatment plant 1 is used to process exclusively the wastewater coming from well-pads W1, W3, most of the wastewater from well-pad W2, and W4 and a fraction of the wastewater from well-pad W5. The water treatment plant 2 processes most of the wastewater from well-pad W5, which has a high concentration of TDS and high wastewater production, and part of the wastewater from well-pad W2 produced in period 12. In total, 1,472.3 million gallons are required to drill and fracture 5 well-pads. The total production of wastewater, composed of flowback water and water linked to the shale formation, is around 572.5 million gallons. From the wastewater, 347.8 million gallons (60.8\%) are processed through primary treatment in water plant 1, 188.9 million gallons (33.0\%) are processed with secondary treatment in water plant 2 , and only 35.8 million gallons (6.3\%) are sent to deep-injection. The water treatment facilities supply in total 221.6 million gallons of treated water for drilling and fracturing operations, additional 1,260.8 million gallon of fresh water are required to supply the demand. The share of fresh water, in the water supply mix, was about $85.6 \%$, while re-use and recycled water accounts for the remaining $14.4 \%$ (see Figure 7). Finally, in this case study the global water intensity, based essentially on water demand, was about 5.30 gallons/MMBtu.

\subsubsection{Case Study B: Spatial and temporal variations in gas composition}

In order to demonstrate the capabilities of the proposed framework in dealing with the general case of the integrated water management and shale gas supply chain design and planning, a further case study which considers the problem without the two assumptions made in order to reduce the complexity of the model was executed and the results 
presented in this section. Specifically, this case study includes the nonlinear constraints for the balance of TDS concentration in the raw water tank in water treatment plants as well as the nonlinear constraints expressing component mass balances, for spatial and temporal variations in gas, in compressor stations and gas processing plants. The presence of these constraint families converts the MILP problem to a mixed integer quadratically constrained program (MIQCP) as noted in section 3.9. The numerical statistics of the model as well as the computational results are shown in Table 6. In this case, bilinear (quadratic) terms are present in the model, and therefore the optimization becomes more challenging. As mentioned previously, the MIQCP problem was solved using GloMIQO, which reported a feasible solution after 70 minutes, the rest of the running time was associated with the improvements of the best bound. The optimization process was interrupted when the computational time exceeded fifteen hours, at which time the optimality Gap was about 7\%. Besides the solver GloMIQO, the following solvers were tested with default options to solve the MIQCP problem: BARON, SCIP, DICOPT, SBB and LINDOGLOBAL. All of them reported trivial solution. The NPV for the best feasible solution was about $\$ 44.54$ million. As in the previous cases, Capex has the highest share of the cost breakdown with $72.5 \%$ of the total cost. Conversely, Opex has the lowest share with a share of $4.7 \%$. Additionally, royalties and taxes have a share of $8.2 \%$ and $14.6 \%$, respectively. Concerning water supply and management, fresh water represents roughly $80.8 \%$ of total water supply, while treated water supplied by primary and secondary technologies represents $11.6 \%$ and $7.6 \%$, respectively. Around $49.4 \%$ of the total wastewater is either re-used or recycled as treated water using primary or secondary technology (see Figure 10). The breakeven cost was estimated to be 3.93 \$/MMBtu and the water intensity around 5.31 gal/MMBtu. Wellpad designs with MaxNPV configuration were chosen for well-pads W1, W2, W3, and W5, while MinWI well-pad configuration was selected for well-pad W4. In total, 62 wells were drilled and fractured during the planning horizon. The selection of a less water intensive design for well-pad W4 is due mainly to the higher TDS concentration on wastewater associated with this well-pad, as explained previously.

The drilling schedule is shown in Figure 11. It is observed that the well-pad with the highest TDS concentration on wastewater, well-pad W4, is drilled just 1 period after well- 
pad W2, the well-pad with the lowest TDS concentration. This decision allows the dilution of the wastewater stream from well-pad W4 with the wastewater produced at well-pad W2 in the input tanks at the water treatment facilities. This situation reaffirms that the TDS concentration on wastewater is an important factor at planning the drilling and fracturing operations on shale formation as well as the water management strategy. Regarding the gas transportation and processing, pipelines with intermediate capacities are installed between well-pads with MaxNPV configuration and either compressor stations or gas treatment plants. The well-pad W4, with MinWI configuration, is connected to compressor station 1 through a pipeline with low capacity. As was pointed out previously in this section, the same pipeline capacity may correspond to different pipeline diameters depending on the distance between the two connected nodes. Additionally, the compressor stations 1 and 2 are connected directly to gas plant 2 through pipelines with intermediate capacities. The compressor stations were installed with low capacity and the gas treatment plant 2 was installed with intermediate capacity. Both water treatment plants are installed at the first quarters of the time horizon. The water treatment plant 1 is installed with high capacity, while water treatment plant 2 is installed initially with low capacity and then expanded three times with high capacity. Methane is delivered from gas plant 2 to the demand center using a pipeline with intermediate capacity, while ethane is delivered using a liquid pipeline with high capacity.

This case study also serves to assess the implications of different model formulations for the same problem. A summary of the results for both case studies is presented in Table 7. The results show significant differences in the optimal decisions reported by the solvers for the two formulations. In both cases, 5 well-pads were selected; however, in the nonlinear case, 4 well-pads were installed with MaxNPV configuration and 1 well-pad with MinWI configuration. By contrast, the results presented for the linear version of the same problem (Case Study A) show that the MaxNPV design was implemented for 3 well-pads and the MaxNPV design was used in 2 well-pads. Accordingly, the total production increased around $21.4 \%$ for the non-linear formulation of the problem. The differences in the well-pad designs are due to a more detailed treatment of wastewater storage in the water treatment facilities. This provides more flexibility in water management which 
allows higher usage of water for drilling and fracturing operations. Gas production profiles as well as cumulative production for the non-linear formulation are shown in Figure 12. The increase in total gas production has profound consequences on the design of the transportation and processing infrastructure, and therefore in the economic performance of the shale gas field. For instance, the investment in water treatment plants increased $95.2 \%$ from $\$ 2.1$ million to $\$ 4.1$ million; the investment in gas treatment plants is $12.6 \%$ higher in the second case and the capital for drilling and fracturing experienced an increment of about $26.5 \%$. The investment in the pipeline network was increased only $6 \%$. On average, the total capital investments in the second case increased around $18.3 \%$. Notably, the total operational costs decreased by $0.9 \%$, which is due largely to the implementation of a different wastewater management scheme. In the linear case, the preferred disposal technology was deep injection of water, whereas the option for discharge into rivers was not selected. Regarding the total water disposal, 35.8 million gallons of water were disposed through deep injection. For the nonlinear case, 71.0 million gallons of treated water were discharge into rivers and only 4.4 million gallons were disposed through deep injection. This resulted in a reduction of $88.4 \%$ of the operational costs associated with wastewater management, which compensates for the increase in capital expenditures associated with the use of recycling wastewater treatment technologies. As a consequence, the increase in gas production leads to a $71.0 \%$ of increase in the NPV. Finally, the breakeven cost was reduced by $3.7 \%$ and the normalized NPV registered a net increase of $40.9 \%$.

Certainly, the 5-well-pad problem offers better economic performance when the effects of variable composition and a more rigorous formulation for variable TDS are taken into account. The drastic changes in the wastewater supply chain suggest that the assumptions in the modeling of the wastewater management are the key to understand the different results. The quality of the wastewater; namely TDS concentration, is a determining factor for the design of the wastewater treatment strategy. The technologies for processing wastewater present limitations on the maximum TDS concentration that can be processed. In the case of wastewater streams with high TDS concentration, the non-linear formulation allows their dilution in the input tanks at the water treatment facilities by blending with 
wastewater streams that has a lower TDS concentration. Since blending cannot be modeled with a linear formulation, the constraint was imposed before the input tank. This ensures that the technical limitations are still valid, however, it restricts the amount of wastewater that can be processed with high TDS, and therefore the solution opts for well-pad designs with lower wastewater production profiles. Despite the fact that the optimal solution for both cases is different, the results of Case B reaffirm the importance of an integrated approach for the design of the shale gas supply chain. Furthermore, an improved formulation of the water processing facilities allows better management of the wastewater which is reflected on the selected designs of the well-pads and therefore on the global production and economics of the shale gas field. Finally, it is important to observe that a more accurate formulation of the design and planning problem for shale gas supply chain imposes significant challenges from a computational viewpoint. For instance, the MILP problem was solved in about 2.12 minutes with optimality gap of $1 \%$, while around 70 minutes were required in order to find a feasible solution to the MINLP problem and roughly 15 hours were needed in order to reduce the optimality gap to be around $7 \%$. A further test was carried out in order to reduce the optimality gap for the MINLP model. This test consists in fixing the binary variables associated with the schedule of drilling operations, according to the previous solution provided by GloMIQO, and running the MINLP model again using the same solver in order to reveal new and better solutions to the problem. After 18.4 hours, the optimal objective function was about $\$ 44.96$ million, with an optimality gap of about $1.4 \%$. The new objective function represents an increase of about $\$ 0.42$ million $(\sim 0.94 \%)$ with respect to the previously reported solution for the same MINLP problem.

\section{Conclusions}

This work addressed the evaluation of shale gas resources, focused on the integration of water management with shale gas supply chain design and planning. First, a comprehensive optimization framework that integrates different tools for simulation of unconventional reservoirs, process modeling and simulation, cost analysis, geographic information systems, as well as optimization tools was developed. In its general formulation, the mathematical framework corresponds to a MIQCP problem. Furthermore, 
two special cases were derived from the general formulation, which allows reduction in the model complexity for dealing with particular scenarios that can be considered when evaluating shale was resources. Then, the framework was used to solve two case studies in which common operations in the exploitation and development of shale gas resources are considered. It was shown that the cost associated with the development of shale gas resources is driven mainly by capital expenditures, which account for about $71.9 \%$ of total cost. The results from Case Study A, with constant gas composition, demonstrated that the schedule of drilling is significantly affected by the methane prices. For instance, the delay of the drilling operations was found to be associated with high methane prices at the end of the time horizon. However, it is important to clarify that high methane prices at the end of the time horizon does not means that production peak should take place in the last periods of the time horizon. Instead, the production peak took place in period 15. The reason for this is that, since we are considering a finite time horizon, the schedule is oriented to offset cumulative gas production with gas prices. Additionally, it was observed that TDS concentration in wastewater has a direct impact on the selection of the well-pad configuration as well as on the schedule of drilling operations. For example, it was observed that well-pads with relatively low TDS concentration are drilled first and then drilling and fracturing operations are carried out in well-pad locations associated with relatively high TDS concentration in wastewater. Moreover, the inclusion of different alternatives for the design of the well-pad in the supply chain design allows a better adapted decision to the production of gas and wastewater. For instance, in most of the locations with poor wastewater quality, more water sensitive designs are chosen. This fact reinforces the importance of the integration of water management with the shale gas supply chain, which has not been addressed in the literature to date. Moreover, the results suggest a close link between the schedule of drilling and fracturing operations and the variability of the methane prices. In Case Study B, it was also demonstrated that the proposed framework can address variations in shale gas composition with time and location as well as wastewater quality issues, i.e. technical restrictions on maximum TDS concentration treatable in water treatment plants. Even though only TDS concentration was taken into account, additional water quality parameters can be easily implemented in the proposed framework. The results from Case Study B confirm the aforementioned 
1114

1115

1116

1117

1118

1119

1120

1121

1122

1123

1124

1125

1126

1127

1128

1129

1130

1131

1132

1133

1134

1135

1136

1137

1138

inferences regarding the effect of TDS concentration on the optimal drilling and water management strategy for the development of the shale gas play. Even more important, Case Study B demonstrated the effectiveness of a more accurate problem formulation of the integrated shale gas supply chain with water management considerations. For instance, an increase of about $71 \%$ on the NPV associated with the development of a shale gas play with 5 potential well-pad locations can be achieved with a problem formulation that accounts for spatial and temporal variations in gas composition as well as for nonlinearities associated with blending wastewater streams in treatment facilities. However, it was also observed that a more accurate formulation entails computational challenges. Therefore, the efficient solution of these problems may require the use of specialized solution approaches that exploit the structure and characteristics of the problem to reduce the complexity of the mathematical model and the computational cost of its solution

Finally, the optimal development plan of shale gas resources depends strongly not only on water availability but also on the properties of the shale formation and the market conditions, for instance methane prices. Consequently, the development of stochastic optimization models are required in order to deal with the uncertainties in water availability, gas production profiles, and gas prices. These issues will be addressed in future work.

\section{Appendix A. Conversion factors}

1 kilometer $(\mathrm{km})=0.62$ miles

1 Cubic foot $\left(\mathrm{ft}^{3}\right) \quad=7.48$ gallons

1 Cubic meter $\left(\mathrm{m}^{3}\right)=264.17$ gallons

1 Barrel $(\mathrm{bbl}) \quad=42.00$ gallons

1 Standard cubic foot of natural gas $(\mathrm{scf})=1,000.0 \mathrm{Btu}$ 


\section{Indices}

$\begin{array}{ll}c, c^{\prime} & \text { Compressor stations } \\ d & \text { Design of well-pads } \\ f & \text { Fresh water sources } \\ g & \text { Gas treatment plant sizes } \\ h & \text { Water plants } \\ i & \text { Products } \\ j & \text { Demand centers } \\ k & \text { Water treatment plant sizes } \\ m & \text { Compressor sizes } \\ p & \text { Gas plants } \\ q & \text { Set of pipeline sizes for gas and liquids products } \\ s & \text { Disposal sites } \\ t, t^{\prime} & \text { Time periods } \\ w & \text { Well-pads }\end{array}$

Sets

jg

$j l$

Set of demand centers of gaseous products

Set of demand centers of liquid products

lcc

Set of feasible connections between compressor stations $c$ and $c^{\prime}$

$l c p$

Set of feasible connections between compressor stations $c$ and gas processing plants $p$

$l f w$

Set of feasible connections between fresh water sources $f$ and well pads $w$

lhs

Set of feasible connections between water treatment plants $h$ and disposal sites $s$

$l h w$

Set of feasible connections between water treatment plants $h$ and well-pads $w$

$l i j$

Set of feasible connections between products $i$ and demand centers

$l w c$

$l w p$

lws

$u$

$v$ $j$

Set of feasible connections between well-pads $w$ and compressor stations c

Set of feasible connections between well-pads $w$ and gas processing plants $p$

Set of feasible connections between well-pads $w$ and disposal sites $s$

Set of pipeline sizes for liquid products

Set of pipeline sizes for gas products 


$\begin{array}{ll}\text { Scalars } & \\ \text { MaxExp } & \text { Maximum number of expansions for gas processing plants } \\ \text { MaxInv } & \text { Maximum budget available for investment } \\ \text { MaxTDS } & \text { Max TDS concentration on water blend for hydraulic fracturing } \\ \text { MaxWell } & \text { Maximum number of wells that can be drilled per period } \\ \text { roy } & \text { Royalty rate } \\ t c & \text { Lead time for installing a new compressor } \\ t d & \text { Lead time for building a pipeline either for liquids or gas } \\ t g & \text { transportation } \\ t h & \text { Lead time for installing a new gas treatment plant } \\ t x & \text { Lead time for installing a new water treatment plant } \\ \gamma & \text { Taxes rate } \\ & \text { Discount rate }\end{array}$

\section{Parameters}

CapDis $(s, t)$

Maximum capacity for disposal sites $s$ in time period $t$

CapexCom $(m, c)$

Capital investments for installing compressor $c$ with capacity $m$

CapexGas $(g, p)$

Capital investments for installing Gas treatment plant $p$ with capacity $g$

$\operatorname{CapexPcc}\left(c, c^{\prime}, q\right)$

CapexPcp $(c, p, q)$

Capital investments for installing a pipeline to transport gas from compressor $c$ to compressor $c^{\prime}$ with a diameter size $q$

Capital investments for installing a pipeline with size $q$ to transport gas from compressor $c$ to gas treatment plants $p$

$\operatorname{CapexPpj}(p, j, q) \quad$ Capital investments for installing a pipeline between gas treatment plants $p$ and demand centers $j$ to transport product type $q$

CapexPwc $(w, c, q) \quad$ Capital investments for installing a pipeline to transport gas from well-pad $w$ to compressor $c$ with a diameter size $q$

CapexPwp $(w, p, q) \quad$ Capital investments for installing a pipeline to transport gas from well-pad $w$ to gas treatment plants $p$ with a diameter size $q$

CapexWate $(k, h)$ Capital investments for installing a water treatment plant $h$ with capacity $k$

CapexWell $(d, w) \quad$ Capital investments for drilling a well-pad $w$ with a design $\mathrm{d}$

$\operatorname{Comp}(i, d, w, t)$ Gas composition of product $i$ for design $d$ in well-pad $w$ and time period $t$

$\operatorname{CostAcq}(f)$ Fresh water cost acquisition for source $f$ supplying well-pad $w$

CostFres $(f, w)$

$\operatorname{CostRech}(h, w)$

$\operatorname{CostRecs}(h, s)$

CostWateh $(w, h)$ Fresh water cost transportation for source $f$ supplying well-pad $w$ Water transportation cost from water treatment plants $h$ to wellpads $w$ Water transportation cost from water treatment plants $h$ to disposal sites $s$

Water transportation costs from well-pads $w$ to water treatment 


\begin{tabular}{|c|c|}
\hline $\operatorname{CostWates}(w, s)$ & Water transportation costs from well-pads $w$ to disposal sites $s$ \\
\hline $\operatorname{Dem}(i, j, t)$ & Demand of product $i$ in demand center $j$ in time period $t$ \\
\hline $\operatorname{Dep}\left(t, t^{\prime}\right)$ & Depreciation rate for investments in time period $t$ during periods $t^{\prime}$ \\
\hline $\operatorname{MaxTDSt}(h)$ & $\begin{array}{l}\text { Max TDS concentration in wastewater for treatment in water plant } \\
h\end{array}$ \\
\hline $\operatorname{NumWell}(d)$ & Number of wells per design $d$ \\
\hline OpexWell $(w)$ & Operational costs for well-pad $w$ \\
\hline OpexCom $(c)$ & Operational costs for compressor $c$ \\
\hline OpexDis $(s)$ & Operational costs for water disposal in site $s$ \\
\hline OpexGas $(p)$ & Operational costs for gas treatment plant $p$ \\
\hline OpexWate $(h)$ & Operational costs for water treatment plant $h$ \\
\hline $\operatorname{Price}(i, j, t)$ & Price for products $i$ paid in demand centers $j$ during period $t$ \\
\hline $\operatorname{PriceC} 3(p, t)$ & Price for $\mathrm{C}_{3+}$ at location of gas plant $p$ during period $t$ \\
\hline $\operatorname{RawTankCap}(k)$ & Size discretization for water tanks \\
\hline $\operatorname{Sizec}(m)$ & Capacity for compressors of size $m$ \\
\hline $\operatorname{Sizeg}(g)$ & Capacity of water treatment plants of size $g$ \\
\hline $\operatorname{Sizeh}(k)$ & Capacity of water treatment plants of size $k$ \\
\hline $\operatorname{Sizep}(q)$ & Size discretization for gas pipelines transportation of size $q$ \\
\hline $\operatorname{Sizepl}(q)$ & Size discretization for liquids pipelines transportation of size $q \mid \in u$ \\
\hline $\operatorname{TankCap}(k)$ & Capacity of water tanks of size $k$ \\
\hline $\operatorname{TDSf}(f)$ & TDS concentration in fresh water sources $f$ \\
\hline $\operatorname{TDSh}(h)$ & TDS concentration in treated water from water plant $h$ \\
\hline $\operatorname{TDS} w(w)$ & TDS concentration in wastewater from well-pads $w$ \\
\hline $\operatorname{WatDem}(d, w)$ & Water demand for fracturing depending on design $d$ and well-pad \\
\hline WateAvai $(f, t)$ & Maximum fresh water availability at source $f$ in time period $t$ \\
\hline $\operatorname{WellGas}(d, w, t)$ & $\begin{array}{l}\text { Gas production profiles corresponding to design } d \text { at well-pad } w \text { in } \\
\text { time period } t\end{array}$ \\
\hline WellWate $(d, w, t)$ & $\begin{array}{l}\text { Water production profiles corresponding to design } d \text { in a well-pad } \\
w \text { in time period } t\end{array}$ \\
\hline$\psi(h)$ & Water Recovery factor for water treatment plant $h$ \\
\hline$\phi(i, p)$ & Separation efficiency for product $i$ in gas treatment plant $p$ \\
\hline
\end{tabular}

\section{Positive continuous Variables}



Capex $(t)$
Total capital investments in time period $t$
$\operatorname{Capex} C O(t)$
Capital investments for in new compressors during time period $t$
CapexGA $(t)$
Capital investments for new gas treatment plants in time period $t$
CapexPI $(t)$
Capital investments for new pipelines in time period $t$
CapexPJ $(t)$
CapexWA $(t)$
Capital investments for new pipelines transporting final products in time period $t$
CapexWE $(t)$
Capital investments for new water treatment plants in time period $t$
$\operatorname{CompC}(i, c, t)$
$\operatorname{Comp} W(i, w, t)$
Capital investments for new well-pads in time period $t$
Compressor output composition for product $i$ in compressor $c$ in time period $t$
$\operatorname{CostCC}(t)$
Well-pad output composition for product $i$ in well-pad $w$ in time period $t$
$\operatorname{CostFW}(t)$
Transportation costs between compressors in time period $t$
$\operatorname{CostHS}(t)$
$\operatorname{CostHW}(t)$
$\operatorname{CostWH}(t)$
$\operatorname{CostWS}(t)$
Total transportation costs for fresh water in time period $t$
Total transportation costs for treated water from water treatment plants to disposal sites in time period $t$
Transportation costs from water treatment plants to well-pads in time period $t$
Transportation costs from well-pads to water treatment plants in time period $t$
Transportation costs from well-pads to disposal sites in time period
$\operatorname{Dep}\left(t, t^{\prime}\right)$
Flow $C C\left(c, c^{\prime}, t\right)$
Depreciation rate factor for investments in time $t$ during periods $t^{\prime}$
Flow $C P(c, p, t)$
Gas flow between compressor $c$ and $c^{\prime}$ in time period $t$
Gas flow from a compressor $c$ to a gas treatment plant $p$ in time period $t$
FlowFW $(f, w, t)$
Fresh water flow from source $f$ to a well-pad $w$ in time period $t$
FlowHS $(h, s, t)$
Treated water flow from water treatment plant $h$ to disposal sites $s$ in time period $t$
Flow $H W(h, w, t) \quad$ Treated water flow from water treatment plant $h$ to a well-pad $w$ in time period $t$
FlowPJ $(p, i, j, t) \quad$ Final products flow from gas treatment plant $p$ sending products $i$ to final demand centers $j$ in time period $t$
Flow WC $(w, c, t) \quad$ Gas flow from a well-pad $w$ to a compressor $c$ in time period $t$
Flow WH $(w, h, t) \quad$ Wastewater flow from well-pad $w$ to water treatment plant $h$ in time period $t$
FlowWP $(w, p, t) \quad$ Gas flow from a well-pad $w$ to a gas treatment plant $p$ in time period $t$
Flow WS $(w, s, t) \quad$ Wastewater flow from well-pad $w$ to disposal sites $s$ in time period $t$ 


\begin{tabular}{|c|c|}
\hline $\operatorname{Opex}(t)$ & Total operational costs in time period $t$ \\
\hline OpexCO $(t)$ & Operational costs for new compressors in time period $t$ \\
\hline OpexDI $(t)$ & Operational costs for disposal in time period $t$ \\
\hline OpexGA $(t)$ & Operational costs for new gas treatment plants in time period $t$ \\
\hline OpexWA $(t)$ & Operational costs for new water treatment plants in time period $t$ \\
\hline OpexWC $(t)$ & $\begin{array}{l}\text { Operational costs for transportation from well-pads to compressors } \\
\text { in time period } t\end{array}$ \\
\hline OpexWE $(t)$ & Operational costs for new well-pads in time period $t$ \\
\hline OpexWP $(t)$ & $\begin{array}{l}\text { Operational costs for transportation from well-pads to gas } \\
\text { treatment plants in time period } t\end{array}$ \\
\hline $\operatorname{Pro}(i, w, t)$ & Individual component flow $i$ from well-pad $w$ in time period $t$ \\
\hline $\operatorname{RawTank}(h, t)$ & Raw water storage in water treatment plant $h$ in time period $t$ \\
\hline $\operatorname{Revec} 3(t)$ & $\begin{array}{l}\text { Income from selling } \mathrm{C}_{3+} \text { hydrocarbons at gas processing plant } \\
\text { locations during period } t\end{array}$ \\
\hline Revenue $(t)$ & Revenue in time period $t$ \\
\hline Royalty $(t)$ & Royalty in time period $t$ \\
\hline ShalProd $(w, t)$ & Shale gas production profile in well-pad $w$ in time period $t$ \\
\hline $\operatorname{Taxes}(t)$ & Taxes in time period $t$ \\
\hline $\operatorname{Trans} \operatorname{Cost}(t)$ & Total water transportation costs in time period $t$ \\
\hline $\operatorname{WateProc}(h, t)$ & $\begin{array}{l}\text { Raw water processed in water treatment plant } h \text { during time } \\
\text { period } t\end{array}$ \\
\hline $\operatorname{WateProd}(w, t)$ & Water production profile in well-pad $w$ in time period $t$ \\
\hline WateTank $(h, t)$ & Treated Water storage in water treatment plant $h$ in time period $t$ \\
\hline
\end{tabular}

\section{Free continuous variables}
CashFlow $(t)$
Cash flow after taxes in time period $t$
NPV
Profit $(t)$
Net present value
Profit after depreciation and operational costs in time period $t$
Binary variables
InstC $(m, c, t)$
$\operatorname{Inst} G(g, p, t)$
$\operatorname{InstH}(k, h, t)$
Equal to 1 if a capacity expansion of size $m$ is selected for a compressor $c$ in time period $t$; 0 otherwise Equal to 1 if a capacity expansion of size $g$ is selected for a gas treatment plant $p$ in time period $t ; 0$ otherwise Equal to 1 if a capacity expansion of size $k$ is selected for a water treatment plant $h$ in time period $t ; 0$ otherwise 

$\operatorname{InstPcc}\left(q, c, c^{\prime}, t\right)$
Equal to 1 if a capacity expansion of size $q$ is selected for a pipeline connecting a compressor $c$ with a compressor $c^{\prime}$ in time period $t ; 0$ otherwise
$\operatorname{InstPcp}(q, c, p, t) \quad$ Equal to 1 if a capacity expansion of size $q$ is selected for a pipeline connecting a compressor $c$ with a gas treatment plant $p$ in time period $t ; 0$ otherwise
$\operatorname{InstPpj}(q, p, j, t) \quad$ Equal to 1 if a capacity expansion of size $q$ is selected for a pipeline connecting a gas treatment plant $p$ with demand centers $j$ in time period $t ; 0$ otherwise
$\operatorname{InstPwc}(q, w, c, t) \quad$ Equal to 1 if a capacity expansion of size $q$ is selected for a pipeline connecting a well-pad $w$ with a compressor $c$ in time period $t ; 0$ otherwise
InstPwp $(q, w, p, t) \quad$ Equal to 1 if a capacity expansion of size $q$ is selected for a pipeline connecting a well-pad $w$ with a gas treatment plant $p$ in time period $t ; 0$ otherwise
PlanSite $(p) \quad$ Equal to 1 is a gas processing plant $p$ is selected, 0 otherwise
WellDes $(d, w, t) \quad$ Equal to 1 if the design $d$ is selected for a well-pad $w$ in time period $t ; 0$ otherwise

\section{Acknowledgments}

The authors would like to acknowledge the financial support from the Colombian Science Council (COLCIENCIAS) and the Colombia Purdue Institute (CPI).

\section{References}

Barbot E, Vidic NS, Gregory KB, Vidic RD. Spatial and temporal correlation of water quality parameters of produced waters from Devonian-age shale following hydraulic fracturing. Environmental Science and Technology. 2013;47:2562-9.

Bazilian M, Brandt AR, Billman L, Heath G, Logan J, Mann M, et al. Ensuring benefits from North American shale gas development: Towards a research agenda. Journal of Unconventional Oil and Gas Resources. 2014;7:71-4.

Bistline JE. Natural gas, uncertainty, and climate policy in the US electric power sector. Energy Policy. 2014;74:433-42.

BP. BP Energy Outlook 2035. 2014 p. 1-96. Available from http://www.bp.com/en/global/corporate/about-bp/energy-economics/energyoutlook.html. 
Brantley SL, Yoxtheimer D, Arjmand S, Grieve P, Vidic R, Pollak J, et al. Water resource impacts during unconventional shale gas development: The Pennsylvania experience. International Journal of Coal Geology. 2014;126:140-56.

Burnham A, Han J, Clark CE, Wang M, Dunn JB, Palou-Rivera I. Life-cycle greenhouse gas emissions of shale gas, natural gas, coal, and petroleum. Environmental science \& technology. 2012;46:619-27.

Bussieck MR, Drud AS. SBB: A new solver for mixed integer nonlinear programming. 2001. Available from http://www.gams.com/presentations/or01/sbb.pdf.

Bustin AMM, Bustin RM. Importance of rock properties on the producibility of gas shales. International Journal of Coal Geology. 2012;103:132-47.

Cafaro DC, Grossmann IE. Strategic planning, design, and development of the shale gas supply chain network. AIChE Journal. 2014;2122-42.

Calderón AJ, Guerra OJ, Papageorgiou LG, Jeffrey J. Financial Considerations in Shale Gas Supply Chain Development. 12th International Symposium on Process Systems Engineering and 25th European Symposium on Computer Aided Process Engineering. 2015a;37:2333-8.

Calderón AJ, Guerra OJ, Papageorgiou LG, Siirola JJ, Reklaitis G V. Preliminary Evaluation of Shale Gas Reservoirs: Appraisal of Different Well-Pad Designs via Performance Metrics. Industrial \& Engineering Chemistry Research. 2015b;.

Castro PM. Tightening piecewise McCormick relaxations for bilinear problems. Computers \& Chemical Engineering. 2015;72:300-11.

Chang Y, Huang R, Masanet E. The energy, water, and air pollution implications of tapping China's shale gas reserves. Resources, Conservation and Recycling. 2014a;91:100-8.

Chang Y, Huang R, Ries RJ, Masanet E. Shale-to-well energy use and air pollutant emissions of shale gas production in China. Applied Energy. 2014b;125:147-57.

Clark CE, Horner RM, Harto CB. Life cycle water consumption for shale gas and conventional natural gas. Environmental science \& technology. 2013;47:11829-36.

Clarkson CR. Production data analysis of unconventional gas wells: Workflow. International Journal of Coal Geology. 2013;109-110:147-57.

Clarkson CR, Jensen JL, Blasingame T. Reservoir Engineering for Unconventional Reservoirs: What Do We Have to Consider?. North American Unconventional Gas Conference and Exhibition. Society of Petroleum Engineers; 2011. p. 72-8. 
Dahaghi AK, Mohaghegh SD. A new practical approach in modelling and simulation of shale gas reservoirs: application to New Albany Shale. International Journal of Oil, Gas and Coal Technology. 2011. p. 104.

Duran MA, Grossmann IE. An outer-approximation algorithm for a class of mixed-integer nonlinear programs. Mathematical Programming. 1986;36:307-39.

Eaton TT. Science-based decision-making on complex issues: Marcellus shale gas hydrofracking and New York City water supply. The Science of the total environment. 2013;461-462:158-69.

ESRI. ArcGIS Desktop: Release 10.2.2. Redlands, CA: Environmental Systems Research Institute. 2014. Available from http://www.esri.com/software/arcgis/arcgis-fordesktop.

Fedotov V, Gallo D, Hagemeijer P, Kuijvenhoven C. Water Management Approach for Shale Operations in North America. SPE Unconventional Resources Conference and Exhibition-Asia Pacific. Society of Petroleum Engineers; 2013.

Field R a, Soltis J, Murphy S. Air quality concerns of unconventional oil and natural gas production. Environmental science Processes \& impacts. 2014;16:954-69.

Gao J, You F. Optimal design and operations of supply chain networks for water management in shale gas production: MILFP model and algorithms for the waterenergy nexus. AIChE Journal. 2015;61:1184-208.

Goodwin S, Carlson K, Knox K, Douglas C, Rein L. Water intensity assessment of shale gas resources in the Wattenberg field in northeastern Colorado. Environmental science \& technology. 2014;48:5991-5.

Gregory KB, Vidic RD, Dzombak D a. Water management challenges associated with the production of shale gas by hydraulic fracturing. Elements. 2011;7:181-6.

Guarnone M, Rossi F, Negri E, Grassi C, Genazzi D, Zennaro R. An unconventional mindset for shale gas surface facilities. Journal of Natural Gas Science and Engineering. 2012;6:14-23.

Heath G a, O'Donoughue P, Arent DJ, Bazilian M. Harmonization of initial estimates of shale gas life cycle greenhouse gas emissions for electric power generation. Proceedings of the National Academy of Sciences of the United States of America. 2014;111:E316776.

Heller R, Zoback M. Adsorption of methane and carbon dioxide on gas shale and pure mineral samples. Journal of Unconventional Oil and Gas Resources. 2014;8:14-24. 
Horner P, Halldorson B, Slutz JA. Shale Gas Water Treatment Value Chain - A Review of Technologies, including Case Studies. SPE Annual Technical Conference and Exhibition. Society of Petroleum Engineers; 2013.

Hou D, Luo J, Al-Tabbaa A. Shale gas can be a double-edged sword for climate change. Nature Climate Change. 2012;2:385-7.

Howarth RW, Ingraffea A, Engelder T. Natural gas: Should fracking stop?. Nature. 2011;477:271-5.

Ingraffea AR, Wells MT, Santoro RL, Shonkoff SBC. Assessment and risk analysis of casing and cement impairment in oil and gas wells in Pennsylvania, 2000-2012. Proceedings of the National Academy of Sciences of the United States of America. 2014;111:1095560.

Jackson RB, Vengosh A, Carey JW, Davies RJ, Darrah TH, O’Sullivan F, et al. The Environmental Costs and Benefits of Fracking. Annual Review of Environment and Resources. 2014;39:327-62.

Jackson RB, Vengosh A, Darrah TH, Warner NR, Down A, Poreda RJ, et al. Increased stray gas abundance in a subset of drinking water wells near Marcellus shale gas extraction. Proceedings of the National Academy of Sciences of the United States of America. 2013;110:11250-5.

Jacquet JB. Review of risks to communities from shale energy development. Environmental science \& technology. 2014;48:8321-33.

Jenner S, Lamadrid AJ. Shale gas vs. coal: Policy implications from environmental impact comparisons of shale gas, conventional gas, and coal on air, water, and land in the United States. Energy Policy. 2013;53:442-53.

Jiang M, Hendrickson CT, VanBriesen JM. Life cycle water consumption and wastewater generation impacts of a Marcellus shale gas well. Environmental science \& technology. 2014;48:1911-20.

Kaiser MJ. Haynesville shale play economic analysis. Journal of Petroleum Science and Engineering. 2012a;82-83:75-89.

Kaiser MJ. Profitability assessment of Haynesville shale gas wells. Energy. 2012b;38:31530.

Kargbo DM, Wilhelm RG, Campbell DJ. Natural gas plays in the Marcellus Shale: challenges and potential opportunities. Environmental science \& technology. 2010;44:5679-84.

Kinnaman TC. The economic impact of shale gas extraction: A review of existing studies. Ecological Economics. 2011;70:1243-9. 
Knudsen BR, Whitson CH, Foss B. Shale-gas scheduling for natural-gas supply in electric power production. Energy. 2014;78:165-82.

Konschnik KE, Boling MK. Shale gas development: a smart regulation framework. Environmental science \& technology. 2014;48:8404-16.

Laurenzi IJ, Jersey GR. Life cycle greenhouse gas emissions and freshwater consumption of Marcellus shale gas. Environmental science \& technology. 2013;47:4896-903.

Lin Y, Schrage L. The global solver in the LINDO API. Optimization Methods and Software. 2009;24:657-68.

Malakoff D. The gas surge. Science. 2014;344:1464.

McCormick G. Computability of global solutions to factorable nonconvex programs: Part IConvex underestimating problems. Mathematical programming. 1976;10:147-75.

McGlade C, Speirs J, Sorrell S. Unconventional gas - A review of regional and global resource estimates. Energy. 2013;55:571-84.

McJeon H, Edmonds J, Bauer N, Clarke L, Fisher B, Flannery BP, et al. Limited impact on decadal-scale climate change from increased use of natural gas. Nature. 2014;514:482-5.

Melikoglu M. Shale gas: Analysis of its role in the global energy market. Renewable and Sustainable Energy Reviews. 2014;37:460-8.

Misener R, Floudas C a. GloMIQO: Global mixed-integer quadratic optimizer. Journal of Global Optimization. 2012;57:3-50.

Misener R, Floudas C a. ANTIGONE: Algorithms for coNTinuous / Integer Global Optimization of Nonlinear Equations. Journal of Global Optimization. 2014;59:503-26.

Mitchell AL, Small M, Casman E a. Surface water withdrawals for Marcellus Shale gas development: performance of alternative regulatory approaches in the Upper Ohio River Basin. Environmental science \& technology. 2013;47:12669-78.

Mohaghegh SD. Reservoir modeling of shale formations. Journal of Natural Gas Science and Engineering. 2013;12:22-33.

Nicot JP, Scanlon BR. Water use for shale-gas production in Texas, U.S. Environmental Science and Technology. 2012;46:3580-6.

Nicot J-P, Scanlon BR, Reedy RC, Costley RA. Source and fate of hydraulic fracturing water in the Barnett Shale: a historical perspective. Environmental science \& technology. 2014;48:2464-71. 
Olmstead SM, Muehlenbachs LA, Shih J, Chu Z, Krupnick AJ. Shale gas development impacts on surface water quality in Pennsylvania. Proceedings of the National Academy of Sciences of the United States of America. 2013;110:4962-7.

Pacsi AP, Sanders KT, Webber ME, Allen DT. Spatial and Temporal Impacts on Water Consumption in Texas from Shale Gas Development and Use. ACS Sustainable Chemistry \& Engineering. 2014;2:2028-35.

Patwardhan SD, Famoori F, Gunaji RG, Govindarajan SK. Simulation and Mathematical Modeling of Stimulated Shale Gas Reservoirs. Industrial \& Engineering Chemistry Research. 2014;53:19788-805.

Patzek TW, Male F, Marder M. Gas production in the Barnett Shale obeys a simple scaling theory. Proceedings of the National Academy of Sciences of the United States of America. 2013;110:19731-6.

Rahm BG, Bates JT, Bertoia LR, Galford AE, Yoxtheimer D a, Riha SJ. Wastewater management and Marcellus Shale gas development: Trends, drivers, and planning implications. Journal of Environmental Management. 2013;120:105-13.

Rahm BG, Riha SJ. Evolving shale gas management: water resource risks, impacts, and lessons learned. Environmental science Processes \& impacts. 2014;16:1400-12.

Rahm D. Regulating hydraulic fracturing in shale gas plays: The case of Texas. Energy Policy. 2011;39:2974-81.

Rivard C, Lavoie D, Lefebvre R, Séjourné S, Lamontagne C, Duchesne M. An overview of Canadian shale gas production and environmental concerns. International Journal of Coal Geology. 2014;126:64-76.

Sahinidis N V. BARON 14.3.1: Global Optimization of Mixed-Integer Nonlinear Programs, User's Manual 2014. 2014. Available from http://www.minlp.com/downloads/docs/baron manual.pdf.

Sherali HD, Adams WP. A hierarchy of relaxations and convex hull characterizations for mixed-integer zero-one programming problems. Discrete Applied Mathematics. 1994;52:83-106.

Siirola JJ. The impact of shale gas in the chemical industry. AIChE Journal. 2014;60:810-9.

Slutz J, Anderson J, Broderick R, Horner P. Key Shale Gas Water Management Strategies : An Economic Assessment Tool. SPE Annual Technical Conference and Exhibition. Society of Petroleum Engineers; 2012.

Sovacool BK. Cornucopia or curse? Reviewing the costs and benefits of shale gas hydraulic fracturing (fracking). Renewable and Sustainable Energy Reviews. 2014;37:249-64. 
Stamford L, Azapagic A. Life cycle environmental impacts of UK shale gas. Applied Energy. 2014;134:506-18.

Stephenson T, Valle JE, Riera-Palou X. Modeling the relative GHG emissions of conventional and shale gas production. Environmental science \& technology. 2011;45:10757-64.

Tawarmalani M, Sahinidis N V. A polyhedral branch-and-cut approach to global optimization. Mathematical Programming. 2005;103:225-49.

Vengosh A, Jackson RB, Warner N, Darrah TH, Kondash A. A critical review of the risks to water resources from unconventional shale gas development and hydraulic fracturing in the United States. Environmental science \& technology. 2014;48:8334-48.

Vidic R, Brantley S. Impact of shale gas development on regional water quality. Science. 2013;340:1235009.

Wang J, Ryan D, Anthony EJ. Reducing the greenhouse gas footprint of shale gas. Energy Policy. 2011;39:8196-9.

Warner NR, Christie C a, Jackson RB, Vengosh A. Impacts of shale gas wastewater disposal on water quality in western Pennsylvania. Environmental science \& technology. 2013;47:11849-57.

Weber CL, Clavin C. Life cycle carbon footprint of shale gas: review of evidence and implications. Environmental science \& technology. 2012;46:5688-95.

Weijermars R. Economic appraisal of shale gas plays in Continental Europe. Applied Energy. 2013;106:100-15.

Weijermars R. US shale gas production outlook based on well roll-out rate scenarios. Applied Energy. 2014;124:283-97.

Weijermars R. Shale gas technology innovation rate impact on economic Base Case Scenario model benchmarks. Applied Energy. 2015;139:398-407.

Wicaksono DS, Karimi I a. Piecewise MILP under- and overestimators for global optimization of bilinear programs. AIChE Journal. 2008;54:991-1008.

Williams-Kovacs JD, Clarkson CR. A new tool for prospect evaluation in shale gas reservoirs. Journal of Natural Gas Science and Engineering. 2014;18:90-103.

Wilson KC, Durlofsky LJ. Optimization of shale gas field development using direct search techniques and reduced-physics models. Journal of Petroleum Science and Engineering. 2013;108:304-15. 
Wu Y, Li J, Ding D, Wang C, Di Y. A Generalized Framework Model for the Simulation of Gas Production in Unconventional Gas Reservoirs. Society of Petroleum Engineers Journal. 2014;19:845-57.

Xia L, Luo D, Yuan J. Exploring the future of shale gas in China from an economic perspective based on pilot areas in the Sichuan basin-A scenario analysis. Journal of Natural Gas Science and Engineering. 2015;22:670-8.

Yang L, Grossmann IE, Manno J. Optimization models for shale gas water management. AIChE Journal. 2014;60:3490-501.

Zoback MD, Arent DJ. The Opportunities and Challenges of Sustainable Shale Gas Developement. Elements. 2014;10:252-4.

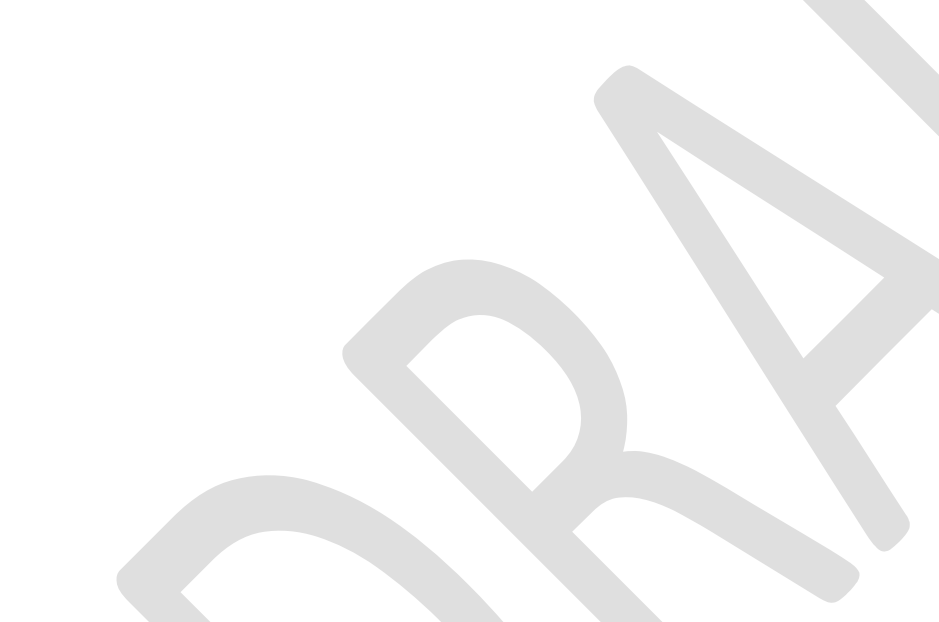

\section{List of Figures}

Figure 1. Schematic of natural gas resources (Source: U.S. Energy Information Administration)..... 57

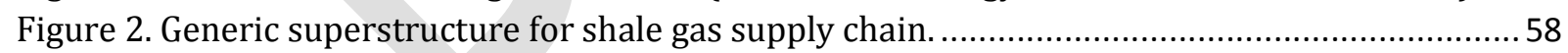

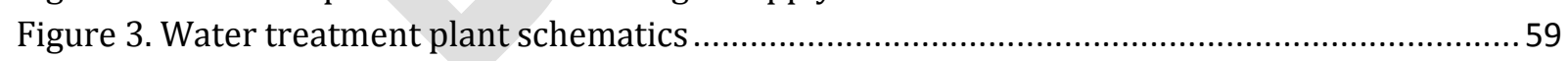

Figure 4. Workflow for the development of an optimization model for shale gas supply chain........59 Figure 5. Gas supply chain (Left-hand side) and water supply chain (Right-hand side) for a case

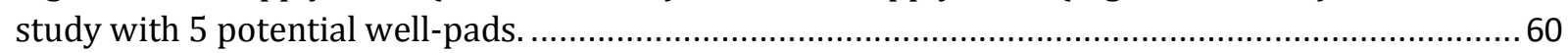

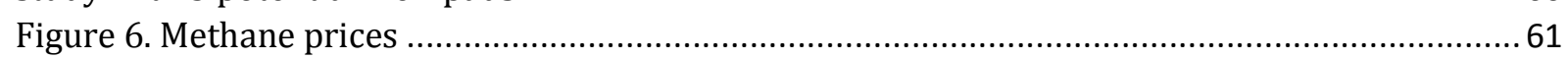

Figure 7. Cost breakdown and water supply mix for Case Study A ...............................................61

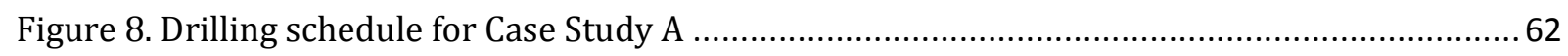

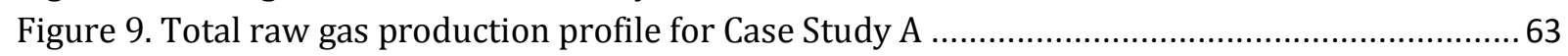

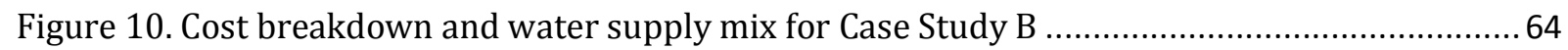

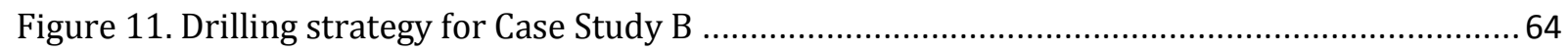




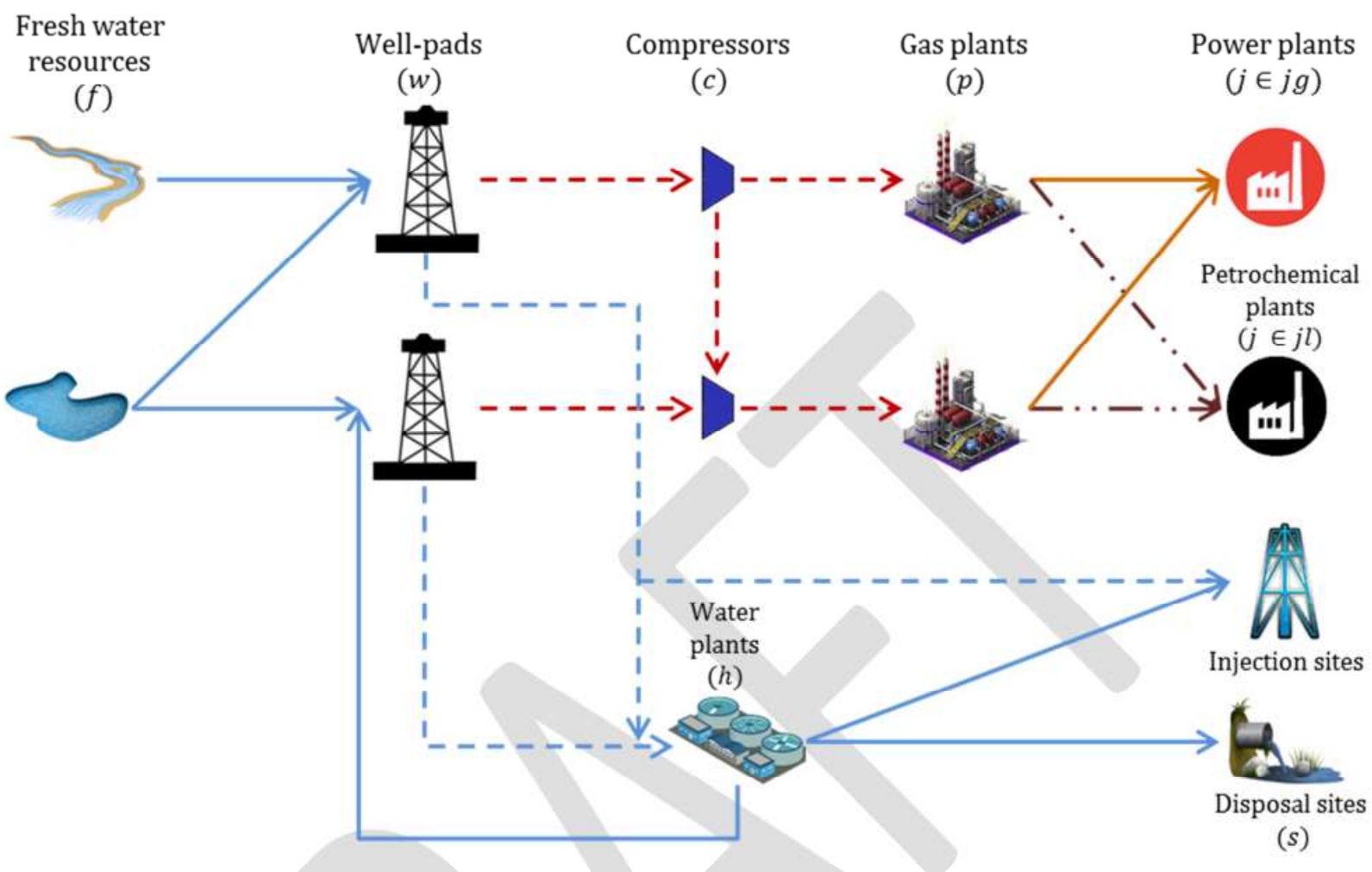

Figure 2. Generic superstructure for shale gas supply chain.

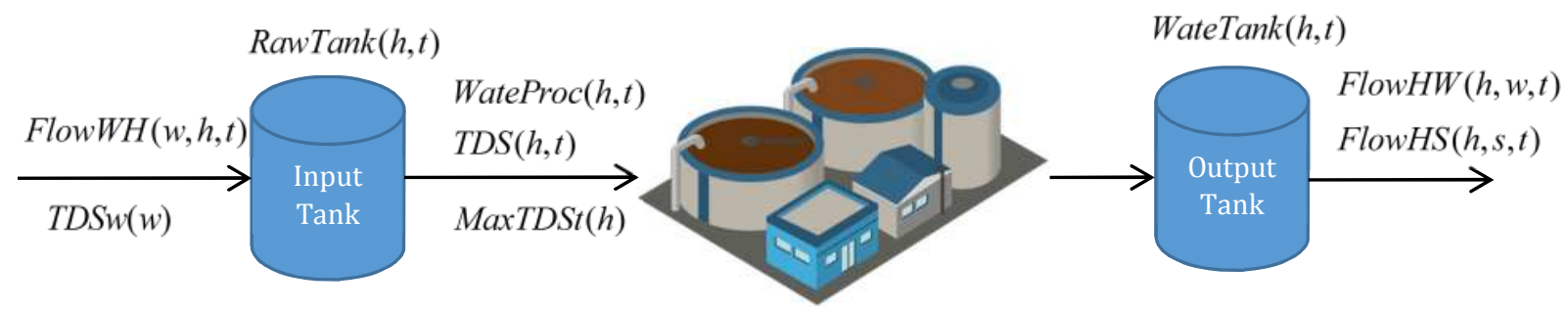



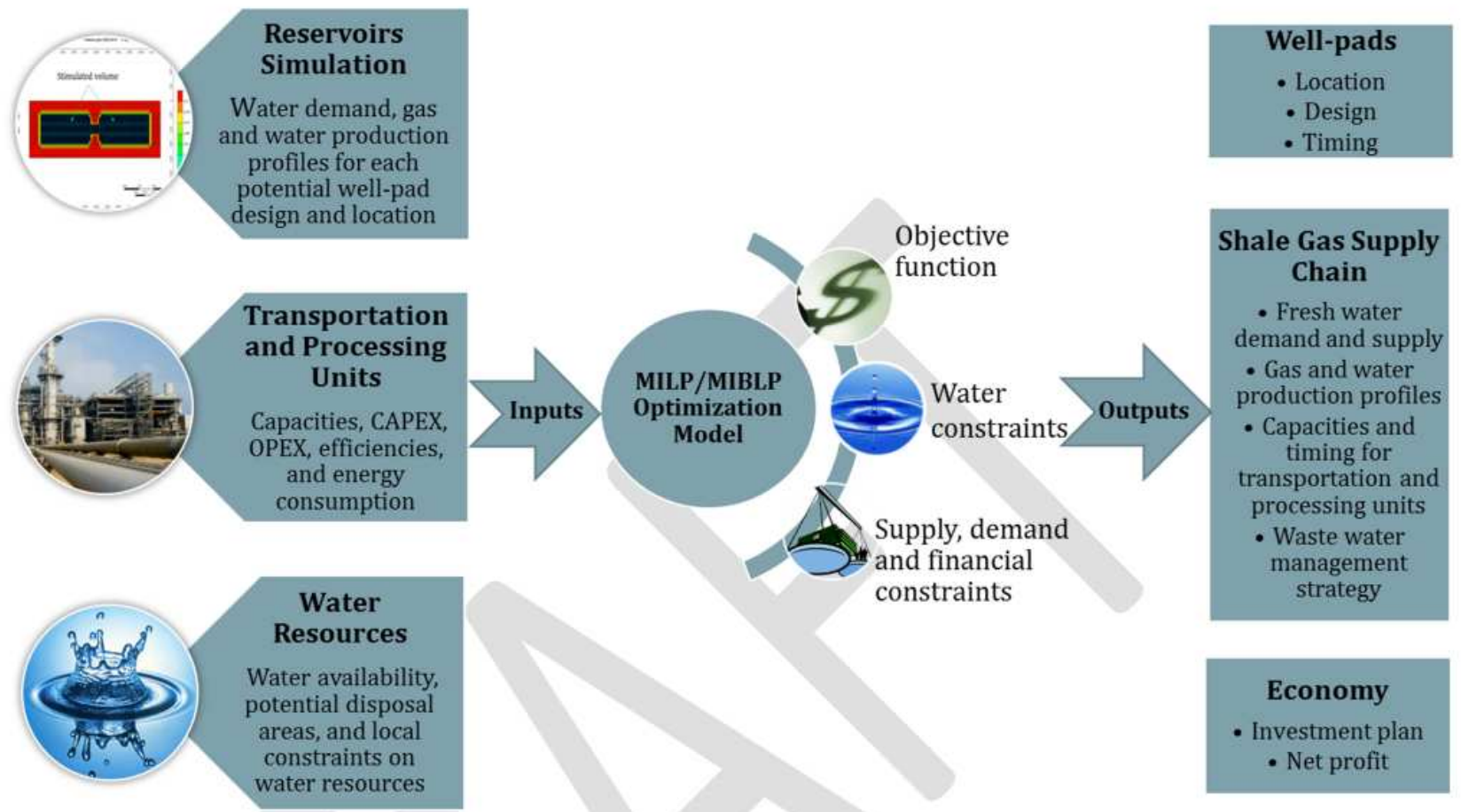

Figure 4. Workflow for the development of an optimization model for shale gas supply chain. 

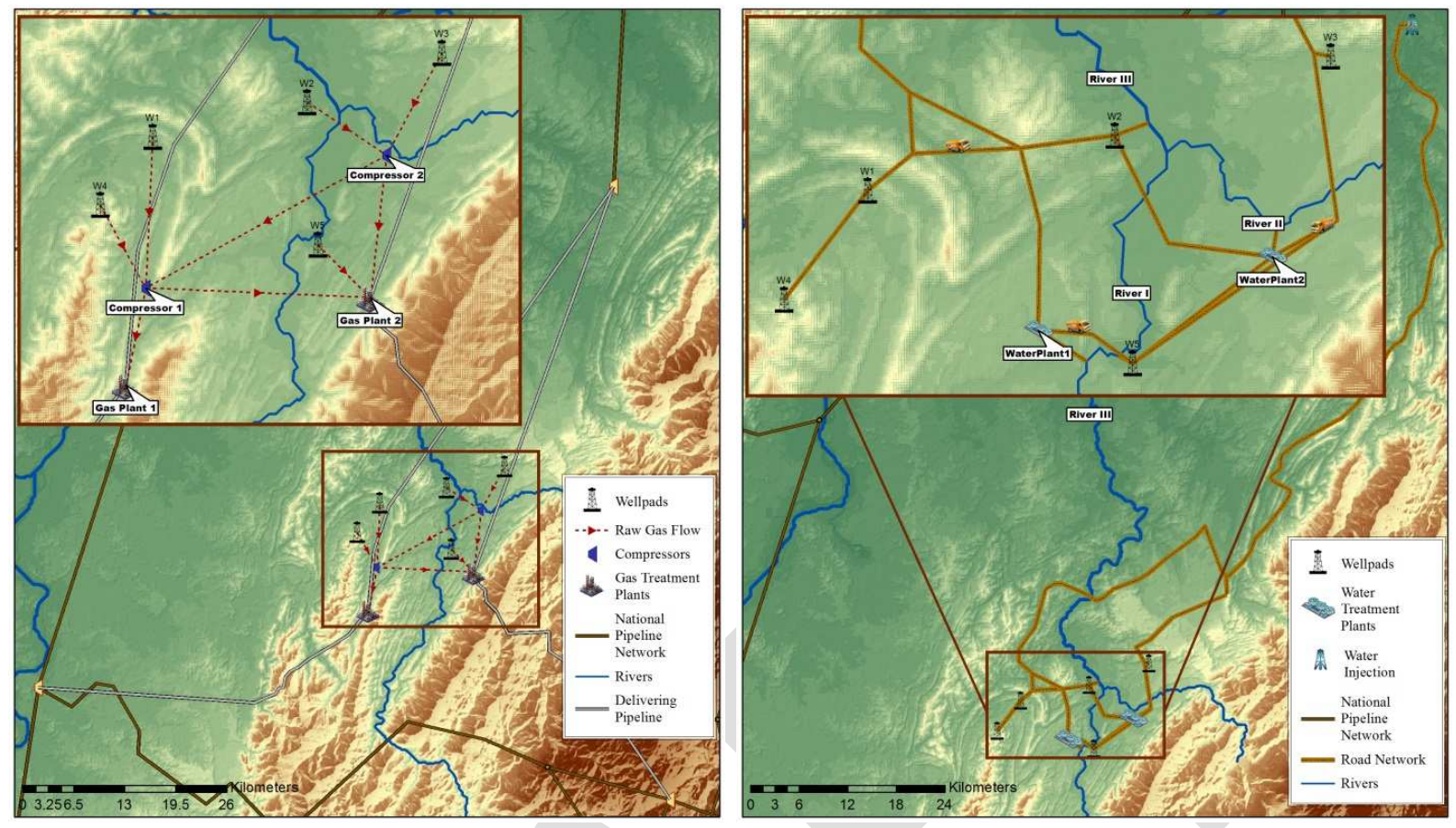

1425

Figure 5. Gas supply chain (Left-hand side) and water supply chain (Right-hand side) for a case study with 5 potential well-pads. 


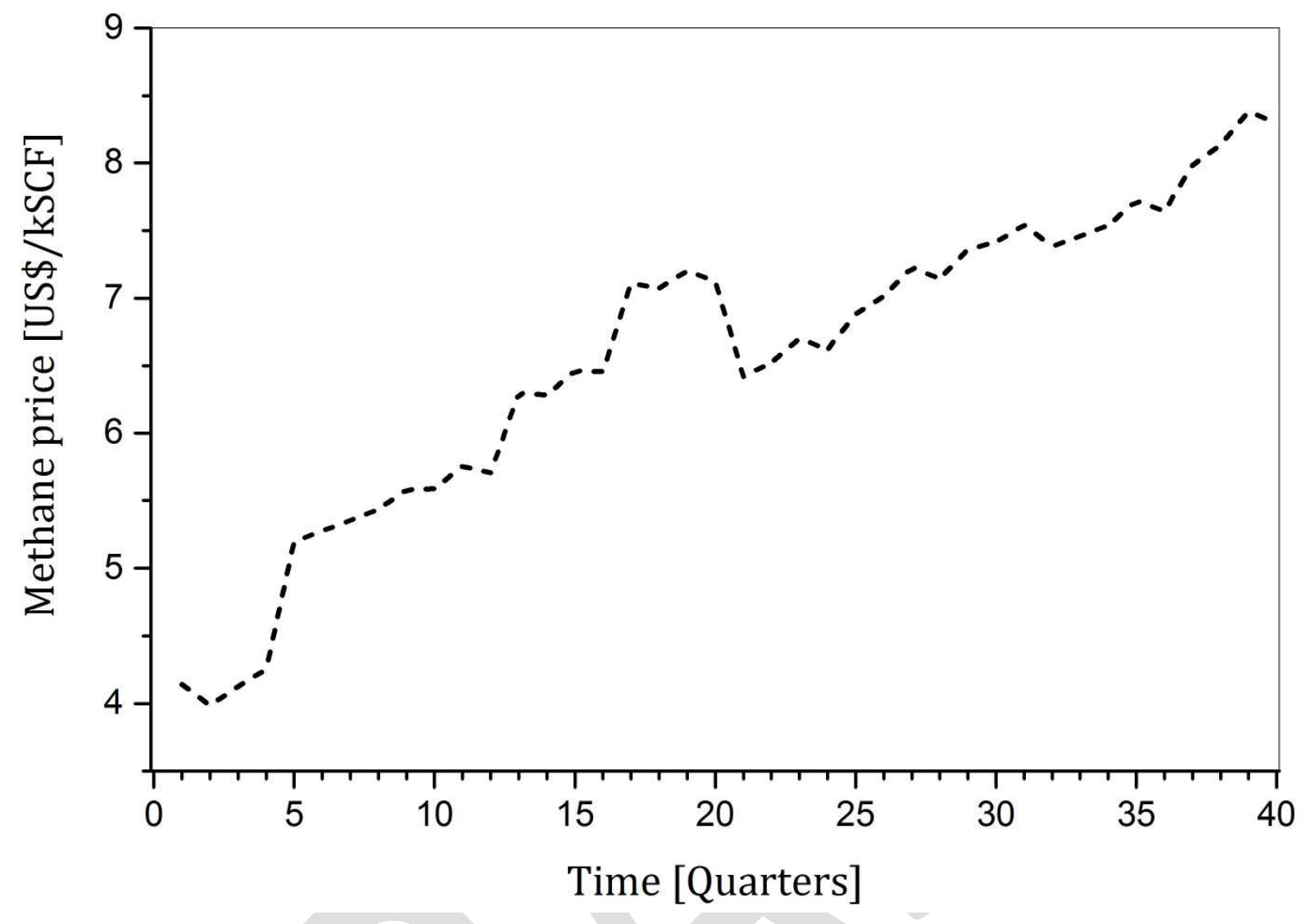

Figure 6. Methane prices

\section{Cost breakdown}
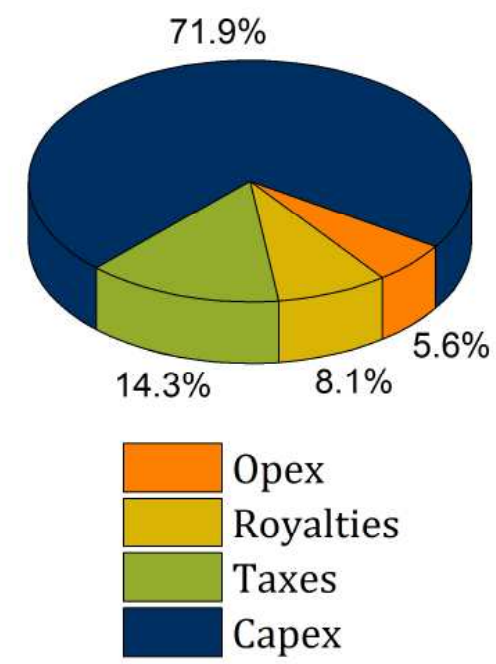

Water supply mix
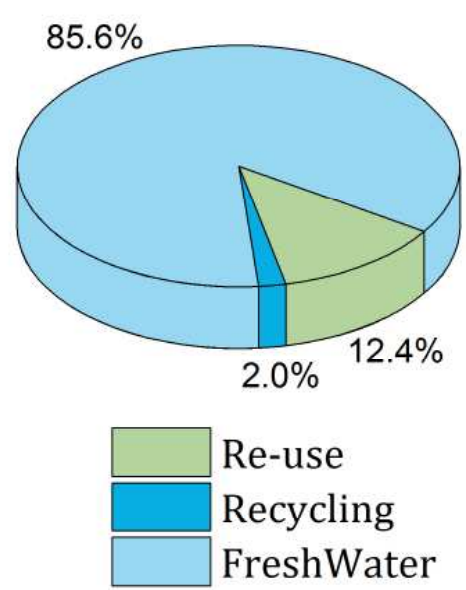

Figure 7. Cost breakdown and water supply mix for Case Study A 


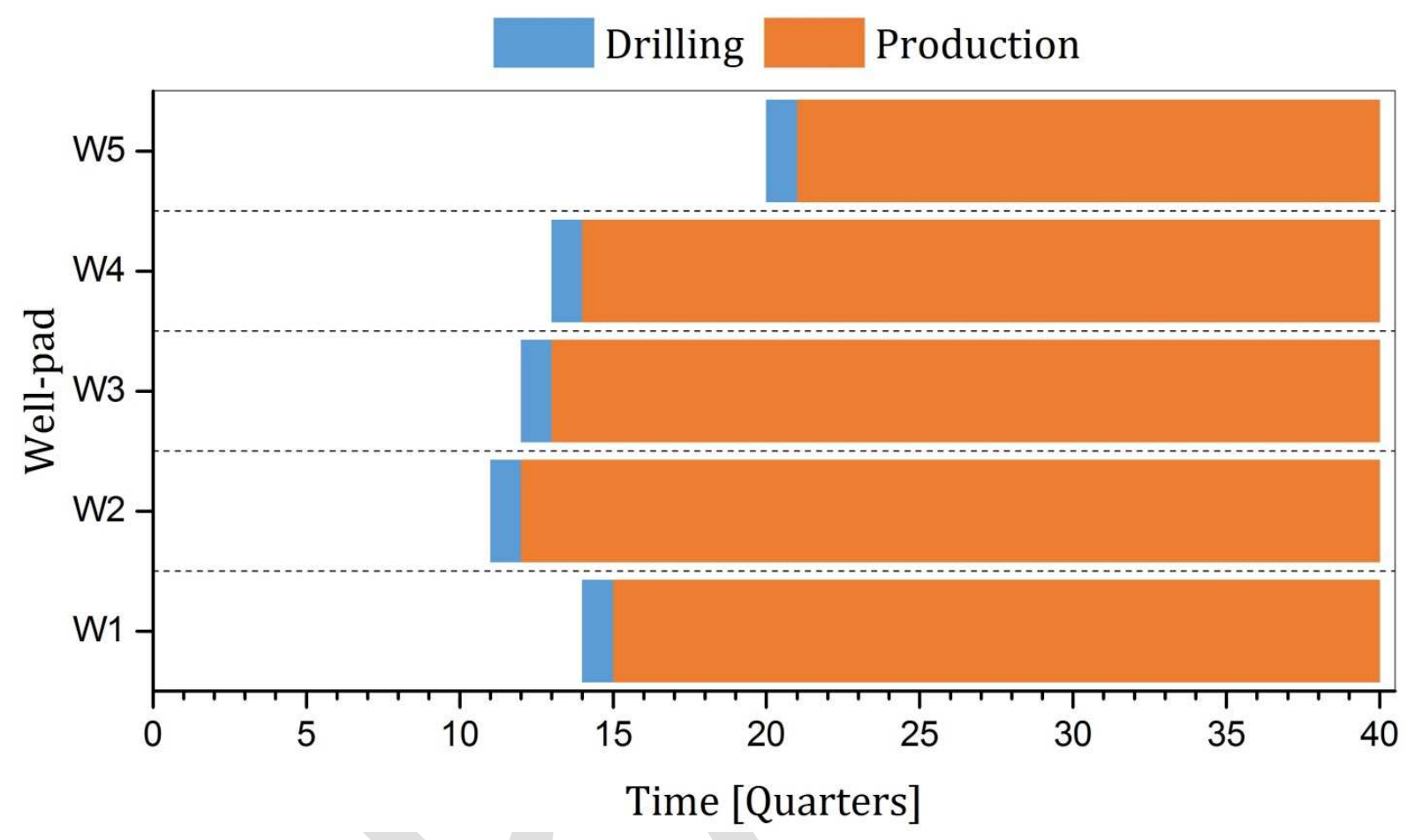

Figure 8. Drilling schedule for Case Study A 

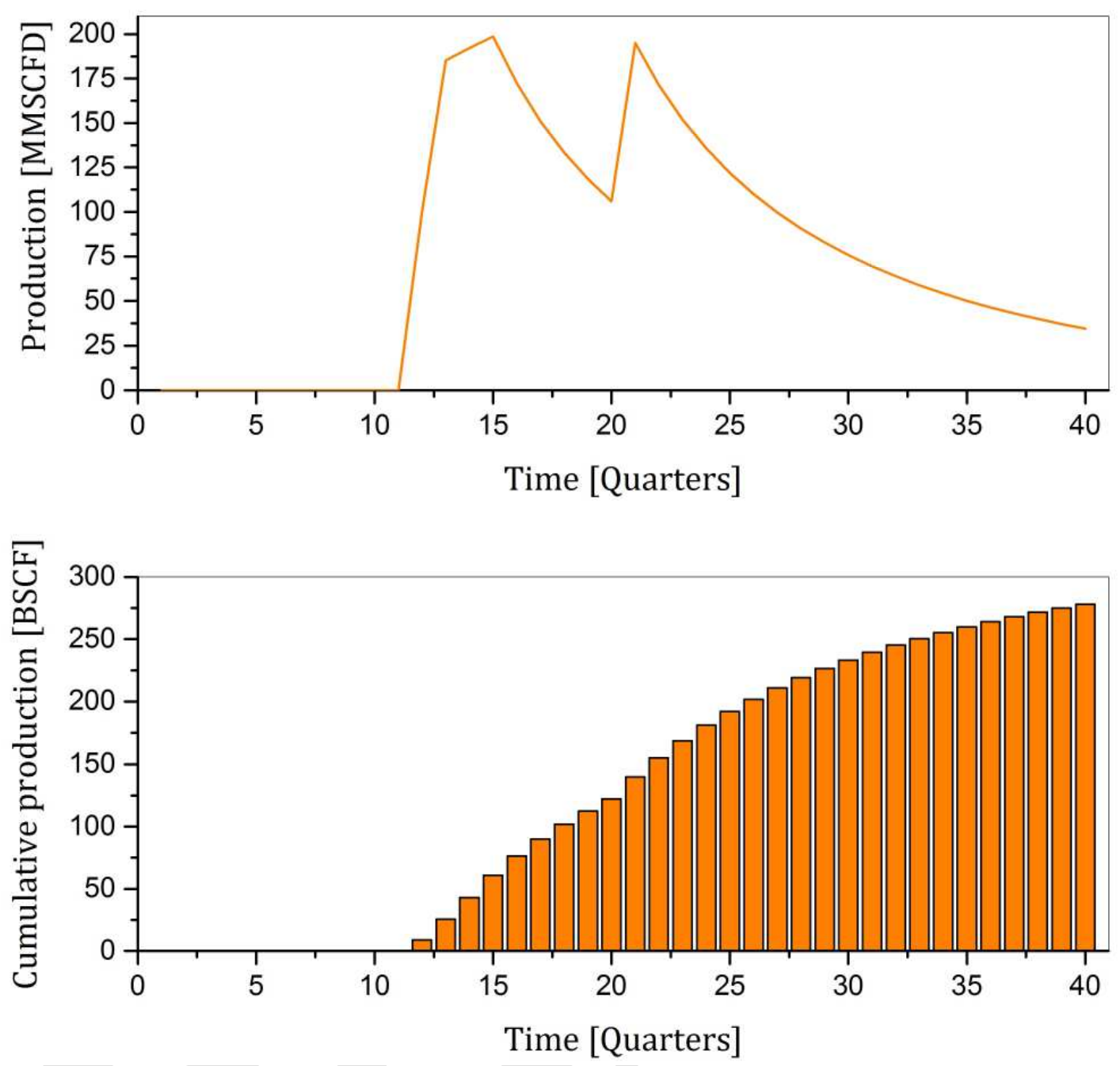

Figure 9. Total raw gas production profile for Case Study A 